\title{
Republic of Croatia: Selected Issues
}

This paper on Selected Issues was prepared by a staff team of the International Monetary Fund as background documentation for the periodic consultation with the member country. It is based on the information available at the time it was completed on October 23, 2012. The views expressed in this document are those of the staff team and do not necessarily reflect the views of the government of the Republic of Croatia or the Executive Board of the IMF.

The policy of publication of staff reports and other documents by the IMF allows for the deletion of market-sensitive information.

\author{
Copies of this report are available to the public from \\ International Monetary Fund • Publication Services \\ $70019^{\text {th }}$ Street, N.W. • Washington, D.C. 20431 \\ Telephone: (202) 623-7430 • Telefax: (202) 623-7201 \\ E-mail: publications@imf.org Internet: http://www.imf.org
}

\section{International Monetary Fund Washington, D.C.}




\title{
INTERNATIONAL MONETARY FUND
}

\section{REPUBLIC OF CROATIA}

\author{
Selected Issues \\ Prepared by Reginald Darius and Géraldine Mahieu
}

Approved by European Department

October 23, 2012

Contents

Page

I. What Has Kept Croatia's Growth Low and How to Boost It? ............................................ 3

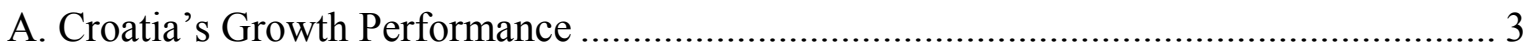

B. The Spence Commission Growth Report ……………................................................ 6

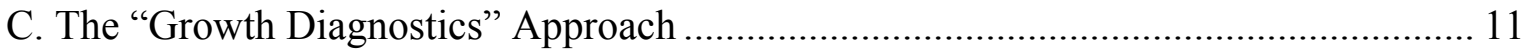

D. The Standard Reform Package or "Washington Consensus" ........................................ 16

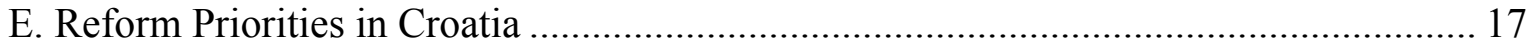

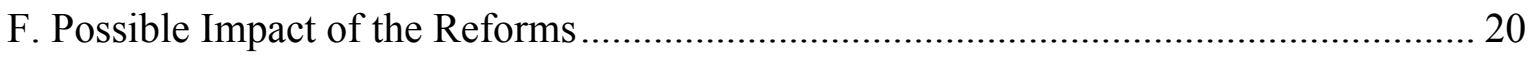

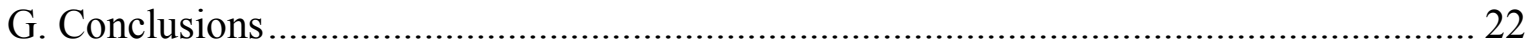

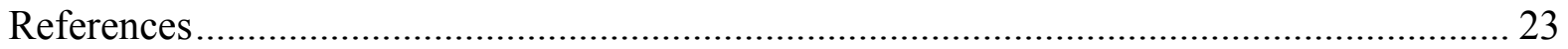

Table

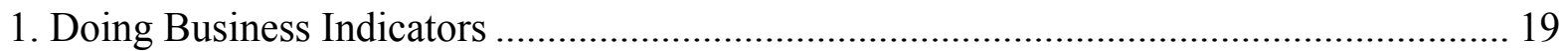

Appendix Figures

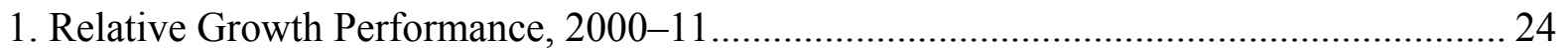

2A. Middle-Income Countries: Growth Accounting, 2000-08 ………................................. 25

2B. Middle-Income Countries: Growth Accounting, 2009-11 ………….............................. 26

3. Middle-Income Countries: Employment Growth Decomposition, 2000-11...................... 27

4. Education Level of the Labor Force ............................................................................ 28

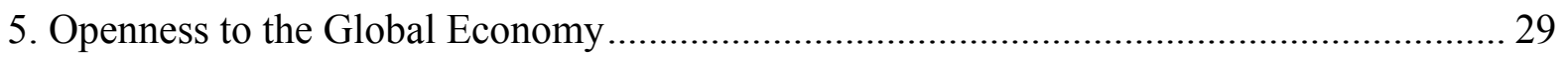

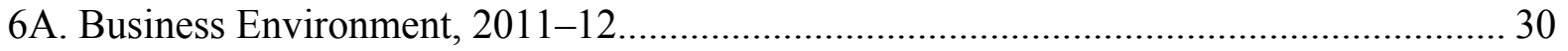

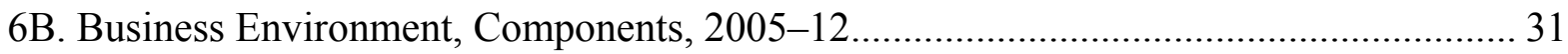

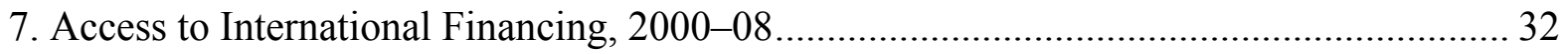

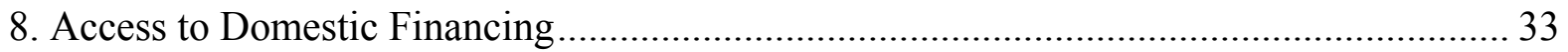

9. Croatia and other Eastern European Countries: Structure of Production by Branches ...... 34

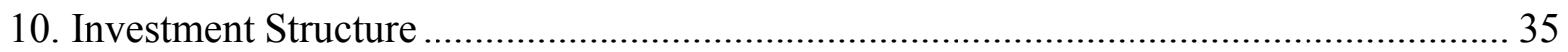

11. EU and US: Average TFP Growth by Sectors, 1995-07, annualized .............................. 36 


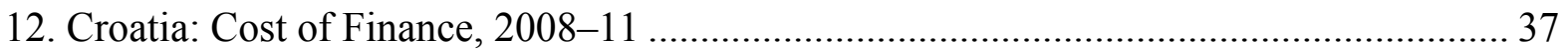

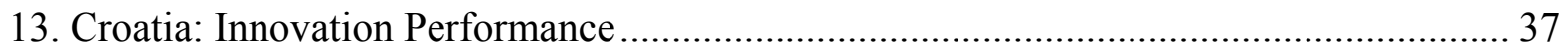

II. Croatia—Export Performance, Wages, and Productivity ….......................................... 38

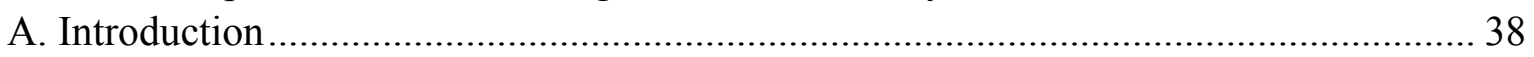

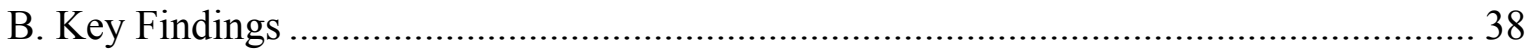

C. Current Account Balance and External Vulnerabilities ............................................ 39

D. Export Performance and Market Share Analysis ........................................................ 40

E. Wages and Export Performance: A Micro Analysis ................................................ 43

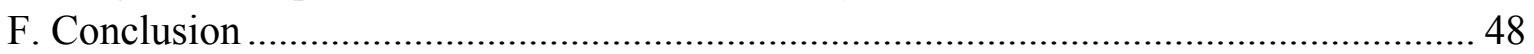

Tables

1. Export Growth Productivity and Wage Gap (P-W) .................................................... 45

2. Export, ULC, and Productivity Growth (correlation), 2000-08 ..................................... 46

3. Market Share (Exports of Eastern Europe to the European Union)................................ 47

Appendix Figures

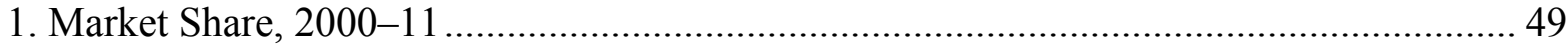

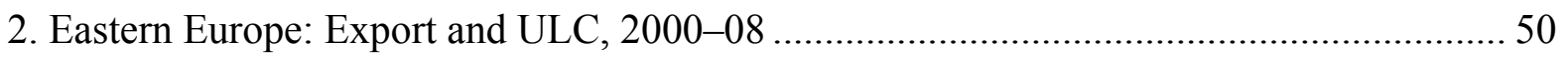

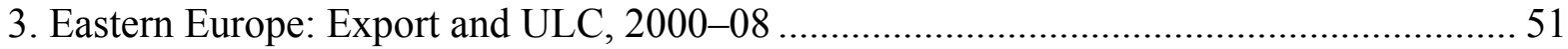

4. Eastern Europe: Export and ULC, 2000-08 ............................................................. 52

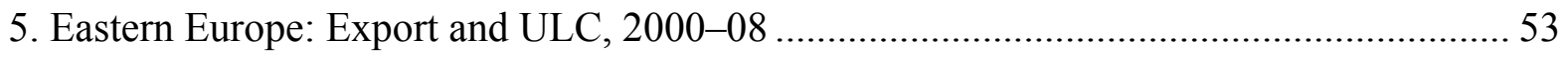

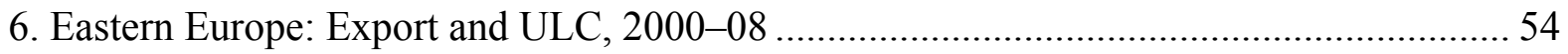




\section{What Has Kept Croatia’s Growth Low AND How to Boost It? ${ }^{1}$}

In the past decade, Croatia's GDP growth has lagged behind growth in most emerging markets including its European peers. Croatia's sub-performance is most notable since the crisis from which it has not yet recovered. The paper investigates the main reasons behind this weak performance and proposes specific policy recommendations to boost growth potential, drawing on three strands of economic thought: (i) the Spence Commission's Growth Report; (ii) the "Growth Diagnostics" approach of Haussmann-Rodrik-Velasco; and (iii) the Washington Consensus. The policy prescriptions coming from these three approaches are very similar: (i) increase work incentives to boost labor force participation and improve labor market flexibility, which will help regain competitiveness; (ii) improve business environment and foster competition to help attract capital, particularly FDI, into the tradable sectors; and (iii) continue the fiscal consolidation efforts to reduce macroeconomic risks and thus improve the cost and availability of capital. Estimates suggest that the impact of these reforms on growth could be quite substantial, potentially raising growth by about 2 percent in the medium to long term.

\section{A. Croatia's Growth Performance}

1. Croatia's GDP growth per capita in 2000-2011 averaged $2 \frac{1}{2}$ percent. This is below the growth performance in most middle-income countries and in most of Croatia's Eastern European peers. ${ }^{2}$ Countries such as Argentina, Peru, Thailand, Slovak Republic, Bulgaria, or the Baltics have achieved substantially higher rate of growth over this period.

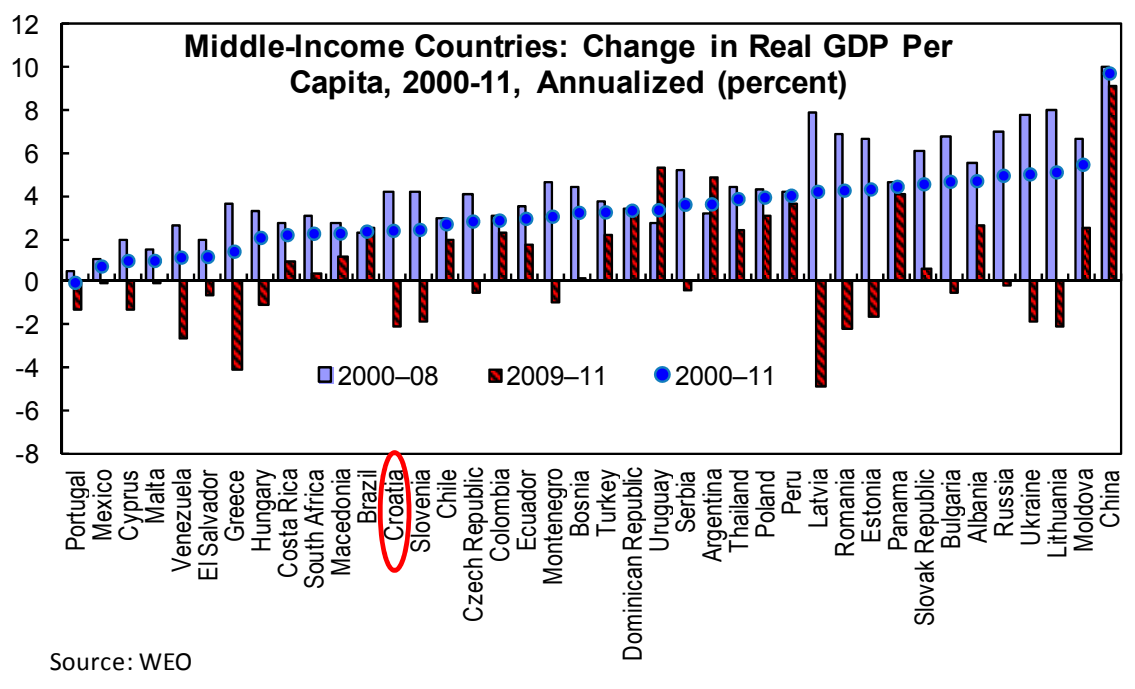

\footnotetext{
${ }^{1}$ Prepared by Géraldine Mahieu.

${ }^{2}$ The peer group of middle-income countries is defined as countries from Europe, Latin America, Asia, and Africa with a mid-level GDP per capita in PPP terms (between the one of Ukraine and Slovenia), plus Moldova. Very small countries and islands are excluded to contain the sample size.
} 


\section{Even accounting for convergence, Croatia's growth performance remains}

modest. Its GDP growth rate in the past decade has been lower than what could be expected, even taking into account its relatively high GDP per capita, while others have done much better by the same metric (text chart).

\section{Croatia's sub-performance is} particularly notable for the last three years. Real GDP growth per capita averaged 4.1 percent over 2000-2008. While this looks relatively sound, this performance is significantly weaker than some of its emerging Europe peers with similar (Estonia, Slovak Republic) and even higher (Czech Republic or Slovenia) initial GDP per capita

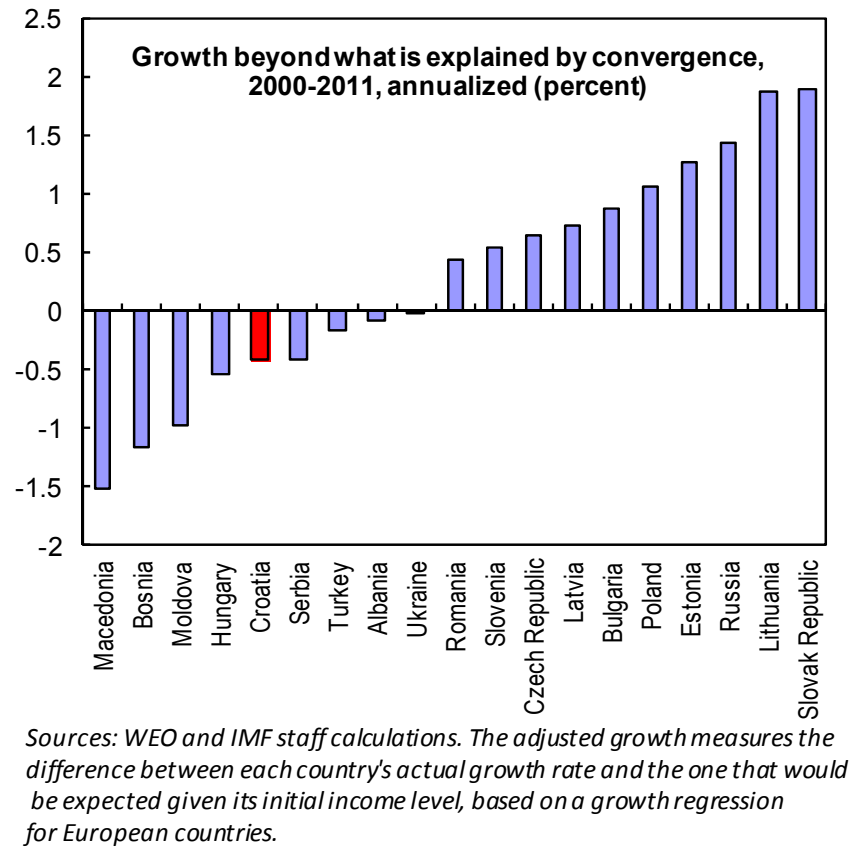

(Appendix Figure 1). The growth differential is even larger in the crisis and post-crisis period where Croatia underperformed most of its middle-income and CEEC peers. ${ }^{3}$ Not only was Croatia hit strongly by the global crisis in 2009 (registering an annual real GDP growth rate of -6.9 percent), but it has not yet recovered from it (with an average annual growth rate of -0.7 percent in the last two years).

\section{Estimates suggest that Croatia's GDP growth has been primarily driven by} capital accumulation. The contribution from total factor productivity was more limited while labor contribution was low. Estimates using a Croatia specific production function ${ }^{4}$ (text table) or based on a cross-countries growth accounting exercise $e^{5}$ (Appendix Figure 2a and $2 \mathrm{~b}$ ) show the same results. As expected during the crisis years, the contribution from capital was reduced due to lower investment while labor and TFP contribution fell strongly and more than in most peers. The relatively low TFP growth in Croatia is puzzling given the high capital accumulation, which is usually conducive to high TFP growth.

\footnotetext{
${ }^{3}$ Croatia's GDP per capita growth rate averaged -2 percent over 2009-2011 compared to 0.7 percent in middleincome countries.

${ }^{4}$ These estimates use a Cobb-Douglas production function with employment share calculated as the total wage bill over GDP ratio (leading to an employment share ranging between $0.4-0.5$ depending on the years).

${ }^{5}$ Following G. Mourre (2009), the growth accounting exercise assumes a constant share of labor of 65 percent while the net capital stock is constructed via the perpetual inventory method (with the capital stock over GDP assumed to be 2 in 1995).
} 


\begin{tabular}{|lccc|}
\hline \multicolumn{4}{|c|}{ GDP growth and contributions } \\
\hline Real GDP Growth & $2000-2008$ & $2009-2011$ & $2000-2011$ \\
Contributions: & 4.3 & -2.8 & 2.5 \\
$\quad$ - capital & & & \\
- labor & 2.6 & 1.5 & 2.3 \\
- productivity & 0.5 & -1.4 & 0.0 \\
\hline
\end{tabular}

5. Unfavorable demographics and low activity rate explain the low contribution of labor to growth before the crisis. Employment growth in Croatia has been lower than in most middle-income and emerging Europe countries (Appendix Figure 3). This is partly due to a very low growth of working-age population as the economy is ageing. ${ }^{6}$ In addition, starting from a relatively low level, the participation rate has further declined over time, while it has increased in other peers such as Estonia or Bulgaria. On the other hand, employment rate has been increasing more in line with peers, although some countries (such as Slovakia, Lithuania, or Bulgaria) have done better. This suggests that the problem in the pre-crisis period may have been predominantly connected with labor supply issues. During the crisis, the fall in employment (about -2.5 percent per year) was one of the most dramatic registered in middle-income countries. This was largely the result of the sharp fall in demand for labor, although falling population and participation rate further worsened the picture. ${ }^{7}$

\section{The growth accounting exercise suggests that Croatia's far-from-perfect pre-} crisis growth model has run its course. The capital accumulation driven pre-crisis growth model did not generate significant productivity gains and its record of employment creation was limited due to labor supply constraints, questioning its sustainability given the growing external debt. Growth significantly fell in 2009 and has not yet turned positive since then. As capital risks being less forthcoming and more expensive in the future than in the pre-crisis period, a fundamental change in Croatia's growth model is needed to return to a reasonable medium-term GDP growth and reverse the sharp increase in unemployment.

7. In order to gain more insight into the reasons behind Croatia's moderate growth performance and provide policy recommendations to boost medium-term growth, the rest of the paper will look into three strands of economic thought: (i) the Spence Commission's

\footnotetext{
${ }^{6}$ The employment growth can be expressed as the combination of four factors: (i) population growth; (ii) growth of the working-age population; (ii) growth of the participation rate; and (iv) growth of the employment rate. Formally, total employment $=$ population * (pop 15-64/population)* (labor force/pop 15-64) * (employment/labor force), with the three ratios being respectively the share of working population, the participation rate and the employment rate.

${ }^{7}$ The decomposition using working age population for the crisis period is not possible due to missing data.
} 
Growth Report; (ii) the "Growth Diagnostics" approach of Haussmann-Rodrik-Velasco; and (iii) the Washington Consensus.

\section{B. The Spence Commission Growth Report ${ }^{8}$}

\section{Content}

8. The report brought together the views of a Commission of 19 leaders, mostly from emerging markets and developing countries, and two academics (Robert Solow and Michael Spence). Their aim was to identify the characteristics of successful growth stories, using 13 high-growth economies (which have grown at an average rate of at least 7 percent a year for at least 25 years) as examples, and explore how other countries could emulate them. The report identified several policy ingredients for growth that could be regrouped into five different categories.

Full exploitation of the global economy

9. High-growth countries fully exploited the opportunities provided by the global economy and were notably characterized by:

- Strong reliance on exports to increase economies of scale and specialization;

- $\quad$ High level of FDI and imported technology, using measures to attract FDI (such as promotion campaigns) and measures to extract more knowledge from foreign investment (via joint venture for instance).

High rate of investment

10. If the high-growth cases are any guide, investment rates above 25 percent (counting both public and private investment) seem needed to grow fast. Strong investment in infrastructure (5-7 percent of GDP), notably in ports, roads, airports, telecommunications and power as well as high investment in human capital (with the combined public and private investment in education, health and training amounting to about 7-8 percent of GDP) appear particularly important.

\section{Macroeconomic stability}

11. During their most successful growth periods, the $\mathbf{1 3}$ high-growth cases avoided large macroeconomic volatility. Factors that seem particularly crucial are:

\footnotetext{
8 The full name is "The Growth Report-Strategies for Sustained Growth and Inclusive Development" by the Commission on Growth and Development, 2008, IBRD.
} 
- $\quad$ Stable and single digit (but higher than 2 percent) inflation;

- $\quad$ Light exchange rate management, which should at best serve two purposes:

(i) slightly favor exports in the early stages of development; (ii) prevent a surge of capital inflows;

- $\quad$ High domestic savings to finance investment;

- $\quad$ Removal of capital controls only when the structural transformation of the economy is well advanced and the financial sector is matured enough.

\section{Market allocation of resources and strong resource mobility}

\section{Governments in high-growth economies did not resist to the process of} structural change and "creative destruction" in their economies. High growth economies were characterized by strong competition and notably easy entry and exit of firms on the market. High mobility of resources (notably of labor) was also a feature of all 13 high-growth cases.

\section{Quality governance}

\section{High-growth economies were leaded by committed, effective, and capable} governments, which: (i) understood that successful development entails a decades-long commitment; (ii) recruited the right persons and gave them the right incentives (salary linked to performance); (iii) were pragmatic in their approach, tried, failed and learned from their mistakes and were ready to change policies when the situation evolved; (iv) exposed their ideas to quality debates (for instance, reform teams composed of a small number of highly qualified and dedicated technocrats were created in Korea, Japan, Malaysia, and Taiwan).

\section{Application to Croatia and policy lessons}

14. With respect to these key growth ingredients, Croatia performed relatively well regarding the investment rate and macroeconomic stability. Investment rates in Croatia averaged 24 percent of GDP in 2000-08, only slightly below the 25 percent minimum level advocated in the Spence Report and comparing favorably with the country's middle-income or emerging Europe peers, even those with high GDP growth rate (text chart). The investment ratio however declined post-crisis, from 28 percent in 2008 to 22 percent in 2011. Investment in infrastructure was also elevated in Croatia (Appendix Figure 10), while the education level of the labor force appears broadly adequate (at least at the secondary education level, while the share of labor force with tertiary education is lower, Appendix Figure 4). Macroeconomic stability has also been largely ensured with an average inflation rate of 2.9 percent in 2000-11, a broadly stable nominal exchange rate providing an anchor for inflation expectations and financial stability, and high level of domestic savings. 

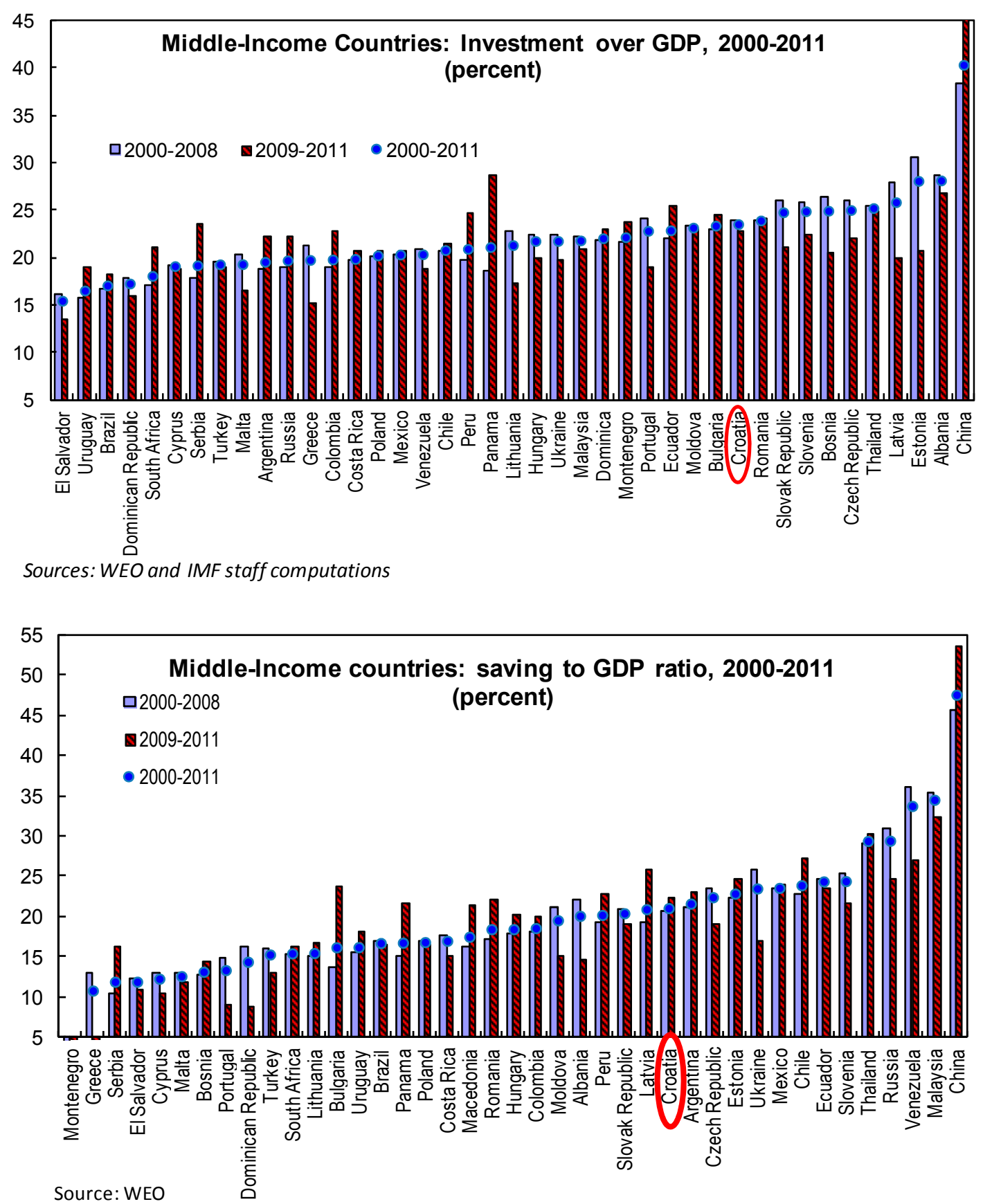

15. However, with respect to the other key growth-generating factors, Croatia's performance has been much less outstanding. While FDI inflows to Croatia (averaging about 5 percent of GDP over 2000-11) have been in line with other middle-income countries, they have been lower than in many other European partners (Appendix Figure 5). In addition, they have largely been directed to non-tradable sectors rather than to manufacturing, limiting their contribution to improving productivity and competitiveness. FDI inflows however sharply fell in 2010-11, notably in non-tradables, reflecting the crisis in the financial sector and the construction bust. 


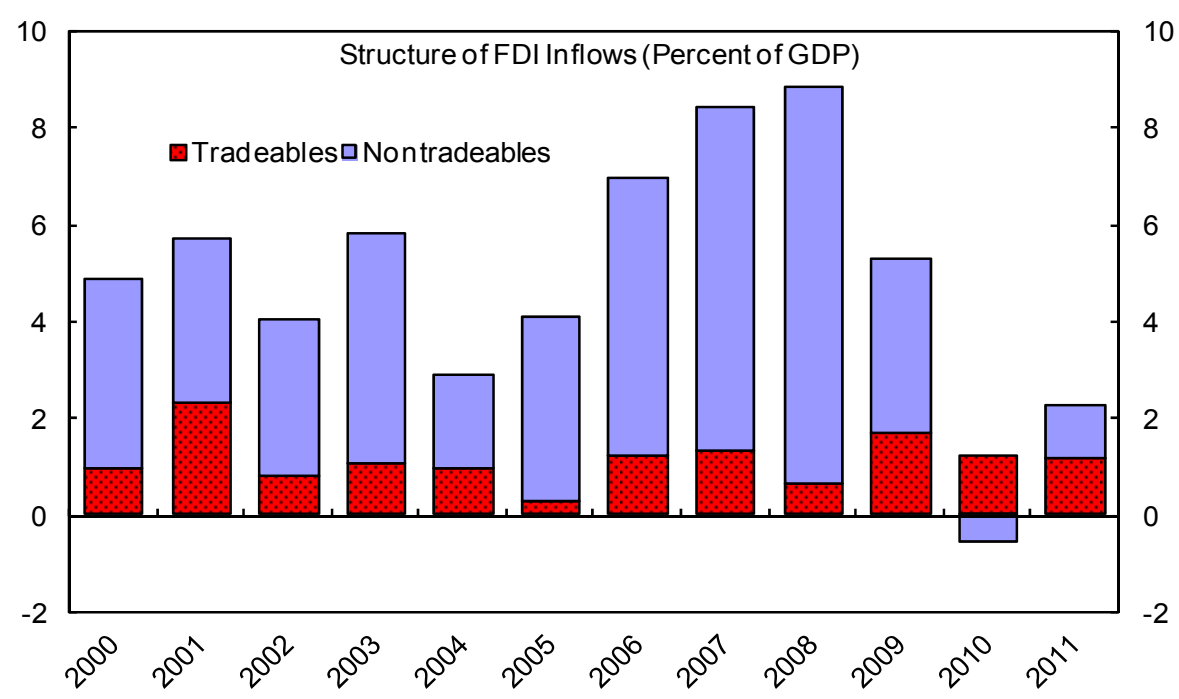

Source: WEO and IMF staff computations

16. Croatia is also a relatively closed economy, with its share of export of goods and services amounting to about 40 percent of GDP, well below the 50-55 percent reached on average in other CEECs or the fast growing middle-income countries (above 70 percent). Croatia's trade openness has also remained strikingly constant over time while its rapidly growing peers enjoyed increasing trade integration which helped them support their GDP growth (Appendix Figure 5).

\section{Labor market flexibility is limited due to strong employment protection and} strict regulations, particularly in the public sector. Hiring and firing costs are high, notably due to high tax wedge on labor, relatively high severance payments, numerous administrative loops for collective dismissals and pro-labor bias of courts, all of which considerably raise dismissal costs. There is also little flexibility to adjust working hours. Collective agreements (with a coverage of 50-60 percent), especially in the public sector, contribute to wage rigidities as, until recently, they could not be changed without explicit trade union agreement and all provisions of a collective agreement of definite duration continued to be valid after it expires until a new agreement has been signed (the so-called "after-effect"). Indicators of structural competitiveness (such as the global competitiveness index or economic freedom index) also point to the lack of flexibility of the labor market as a key obstacle to investment in Croatia. Rigid labor market regulations as well as generous social benefits (notably the low penalty for early retirement, low statutory age of retirement, generous sick leave benefits) have led to a very low labor force participation, among the lowest in middle-income countries, as well as very high unemployment (13 percent in 2011). 


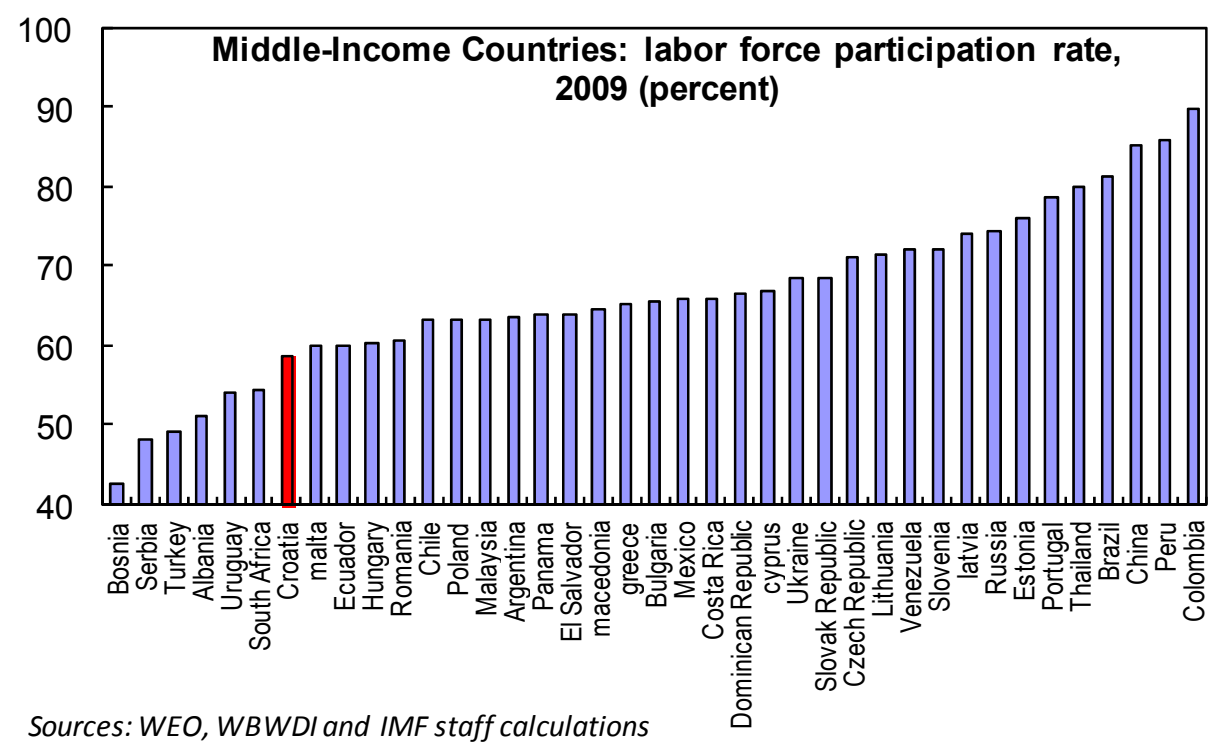

18. Croatia also ranks poorly in terms of competition and product market efficiency, as reflected in the indicators of business environment (Appendix Figures 6a and 6b). These indicators all points to the same deficiencies, namely the high taxation, the high regulatory obstacles for starting or conducting a business (and particularly the slow procedures for obtaining a construction permit and registering a property and barriers to investment at the local government level), the inefficient legal framework (poor competition policy, low investor protection, slow resolution of insolvency), the inefficient and wasteful government spending and the slow process of privatization and enterprise restructuring. On the positive side, Croatia ranks well on infrastructure and education, and moderately well on macroeconomic environment (except on budget balance).

\section{Finally, several governments have been slow in addressing the long-standing} competitiveness problems. The government launched a comprehensive and well-targeted reform package called the Economic Recovery Program (ERP) in April 2010. However, implementation has been slow and patchy due to strong resistance from vested interests. Progress has been made in some areas (notably reduction in health expenditures and unemployment benefits, pension reform), but very limited reforms have been launched to foster labor market flexibility, improve business climate, and reduce the size of the public sector. The general government wage bill is higher than in most new EU member states, mainly as a result of high public sector employment. In addition, a highly compressed pay structure and poor link between salary and performance work as a disincentive to attract and retain quality workers in the public sector.

20. If these $\mathbf{1 3}$ high-growth cases are any guide, the key policy recommendations for Croatia would be:

- $\quad$ increase labor market flexibility; 
- $\quad$ improve business environment;

- $\quad$ improve government efficiency, through administration rationalization and reform of the pay structure.

These reforms are likely to facilitate economic restructuring, foster competition, and help attract more capital in the tradable sector, thereby increasing Croatia's competitiveness and openness.

\section{The "Growth Diagnostics" Approach}

\section{The methodology}

\section{Haussmann, Rodrik, and Velasco (2005) develop a framework for growth} diagnostics that identifies the binding constraints on growth in a country. The goal is to help set up the policy priorities which will provide the biggest bang for the reform buck and hence use the scarce political capital of reformers most efficiently. The framework is based on two equations:

- $\quad$ One for capital accumulation per capita, which is a function of the difference between the rate of return on capital net of tax and the world interest rate;

- $\quad$ Another one expresses the rate of return on capital as a function of total factor productivity (TFP), complementary factors of production, and externalities.

\section{The exercise of growth diagnostics simply consists of reviewing and analyzing} these factors to ascertain by a process of elimination which are the most binding constraints on growth. The main idea of the analysis is that if one factor is scarce and a binding constraint for growth, its price should be elevated and economic growth higher when the constraint is relaxed. The decision tree below helps to identify the most binding constraint on growth. The starting point is to determine whether the problem of low investment is due to too high cost of financing or low private return on domestic investment. Depending on the answer to this question, the analysis moves along the decision tree to identify where the most problematic issue is. 
Problem: low levels of private investment and entrepreneurship

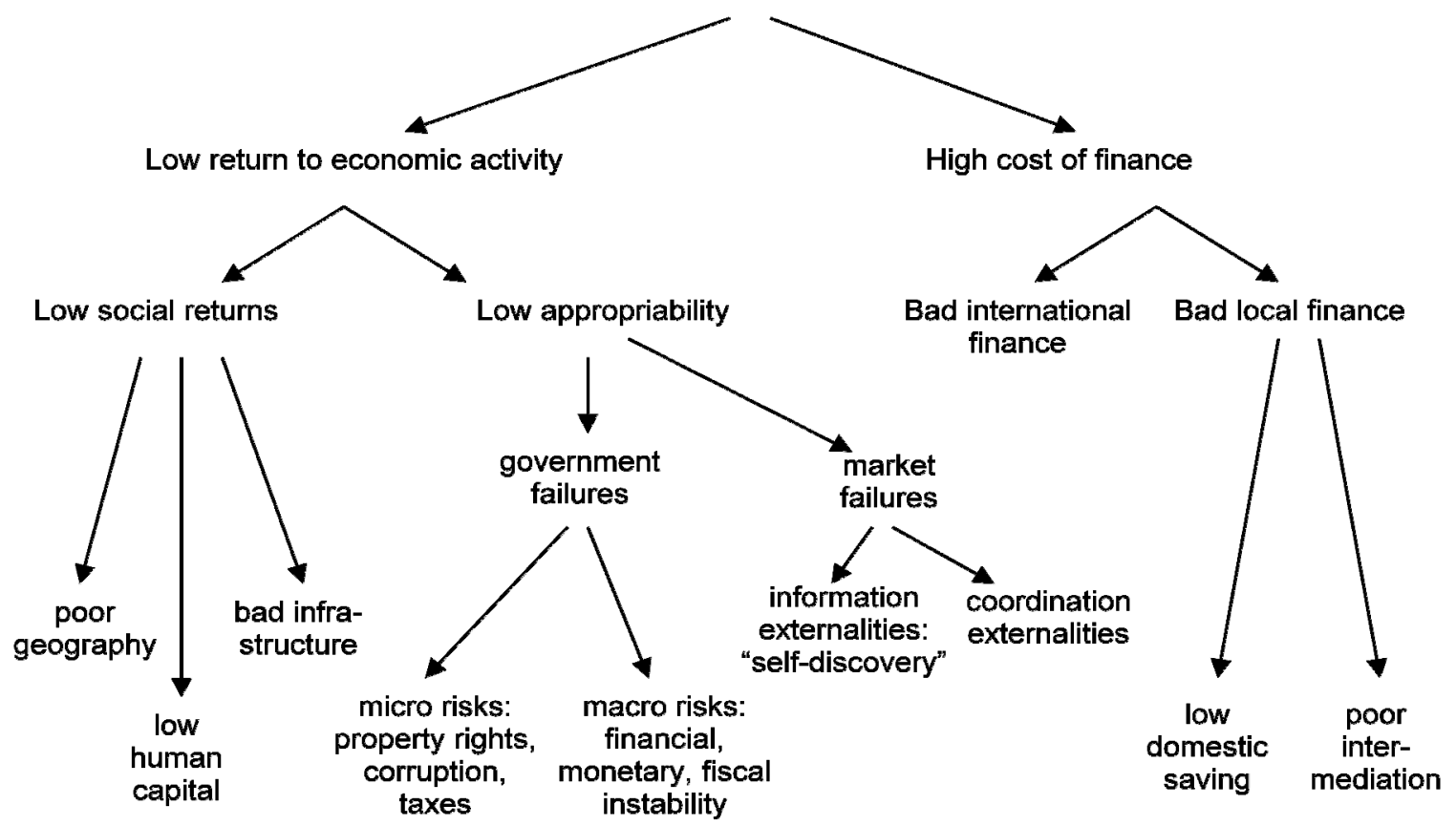

\section{Application to Croatia}

The pre-crisis period

23. Applying the growth diagnostic to Croatia suggests that during the pre-crisis period (2000-08), capital accumulation does not seem to have been the binding constraint to growth. Several elements support this conclusion:

- Low rate of investment? As seen in the previous section, Croatia's investment to GDP ratio at 24 percent in 2000-2008 does not seem low compared to its peers (Appendix Figure 7).

- Bad international finance? The large capital inflows to Croatia in the last decade suggest that Croatia was able to attract foreign savings. Also interest on bonds as shown by the CDS spreads were relatively moderate compared to Croatia's peers and declining during the period (Appendix Figure 7).

- $\quad$ Bad local finance? Domestic savings were ample, while relatively low and decreasing interest rates on loans and deposits do not suggest scarce capital. Real lending rates for corporates were relatively close to real GDP growth in 2000-2008, also not indicating any major issues with the cost of capital (Appendix Figure 8).

24. This exercise seems therefore to suggest that prior to the crisis the major constraint on Croatia's growth has not been the low level of investment but the poor 
allocation of this investment. This is probably due to an inefficient allocation of capital into low valued-added sectors and overall low production efficiency:

- As shown above, Croatia's total factor productivity improvement over 2000-2008 has indeed been lower than in most of its Eastern European partners.

- $\quad$ The structure of production was also largely titled towards non-tradable sectors, with a particularly low share of industry (Appendix Figure 9).

- $\quad$ Also, capital flows, including FDI, were mostly directed towards consumption-related and inward-oriented sectors rather than towards productivity enhancing investment. Investment in industry averaged only 20 percent, significantly less than in other CEECs. On the other hand, Croatia invested significantly more than its peers in financial, construction and tourism sectors (Appendix Figure 10).

- $\quad$ Evidence for the EU and the US shows that these non-tradable sectors were in general a weaker source of productivity growth (Appendix Figure 11). The inefficient allocation of capital in Croatia could hence explain the low TFP and GDP growth in the pre-crisis period despite the relatively strong investment ratio.

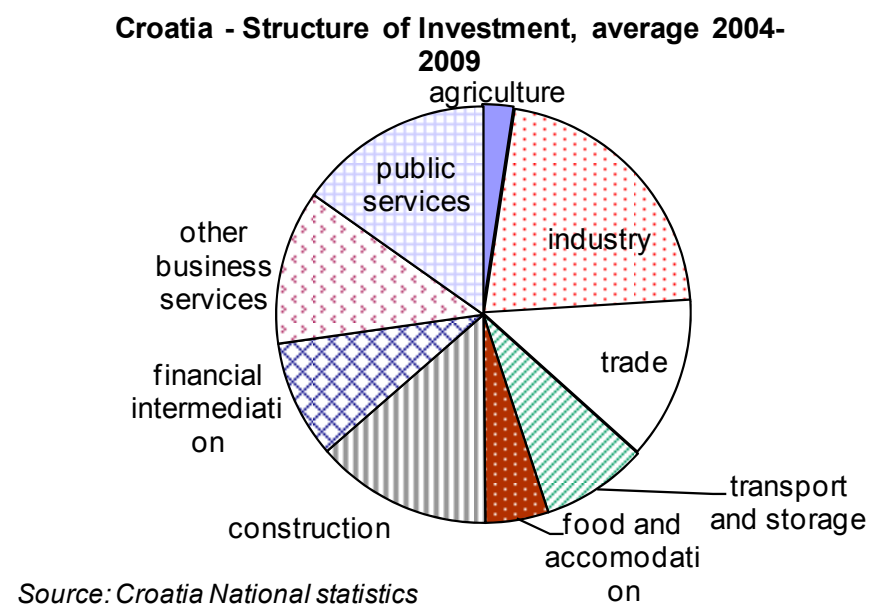

Crisis years (2009-2011) and future growth

25. While the level of investment does not seem to have been a constraint in the precrisis period, it could have become one since the crisis. As noted above, investment has fallen sharply since 2009 with total and private gross fixed capital formation decreasing by more than 10 percent annually over the last three years, leading to a much lower contribution of capital accumulation to growth. FDI inflows have more than halved since 2009. As above, a process of elimination based on the decision tree could help identify the key constraint for growth. 
- High cost of finance? International finance has become scarcer since 2009 with lower capital inflows, higher global risk aversion and higher CDS spreads for Croatia (text chart and Appendix Figure 12). There is a risk that capital flows may be less forthcoming in the future given Croatia's elevated external debt to GDP ratio and low growth prospects, possible further deleveraging by euro area banks, and better country differentiation by markets, although EU accession could help boost capital inflows in the medium-term. In addition, while domestic savings has remained relatively high and deposit rates moderate, credit growth has fallen significantly since early 2009. Real lending rates are also above their pre-crisis level, reflecting higher banks' funding costs and the need for banks to keep lending-deposit spreads elevated to compensate for growing provisions for NPLs.

- Low social returns? Social returns remain high with Croatia's central location in Europe, ready access to the sea and long coastline underpinning its tourism industry. As said above, public expenditure on infrastructure and education has been high and does not seem to be a major constraint for growth.

- Low appropriability owing to elevated risks? Market failures do not appear to have been a major issue in Croatia given reasonable levels of innovation (with R\&D expenditure and patents granted broadly in line with its peers, Appendix Figure 13). However, large fiscal deficits have significantly increased public debt level, with debt dynamics being now unsustainable in the absence of strong fiscal consolidation. External vulnerabilities have also increased over last years with external debt reaching 100 percent of GDP, external financing requirement of about a third of GDP, and a high degree of euroization. In addition, the poor business environment (as detailed above) and well as the high wage and taxation level have likely impeded growth. Using Haussmann, Rodrik and Velasco's terminology, higher macro and micro risks have reduced the return of investing in Croatia, thereby contributing to the decline in capital inflows and investment. 


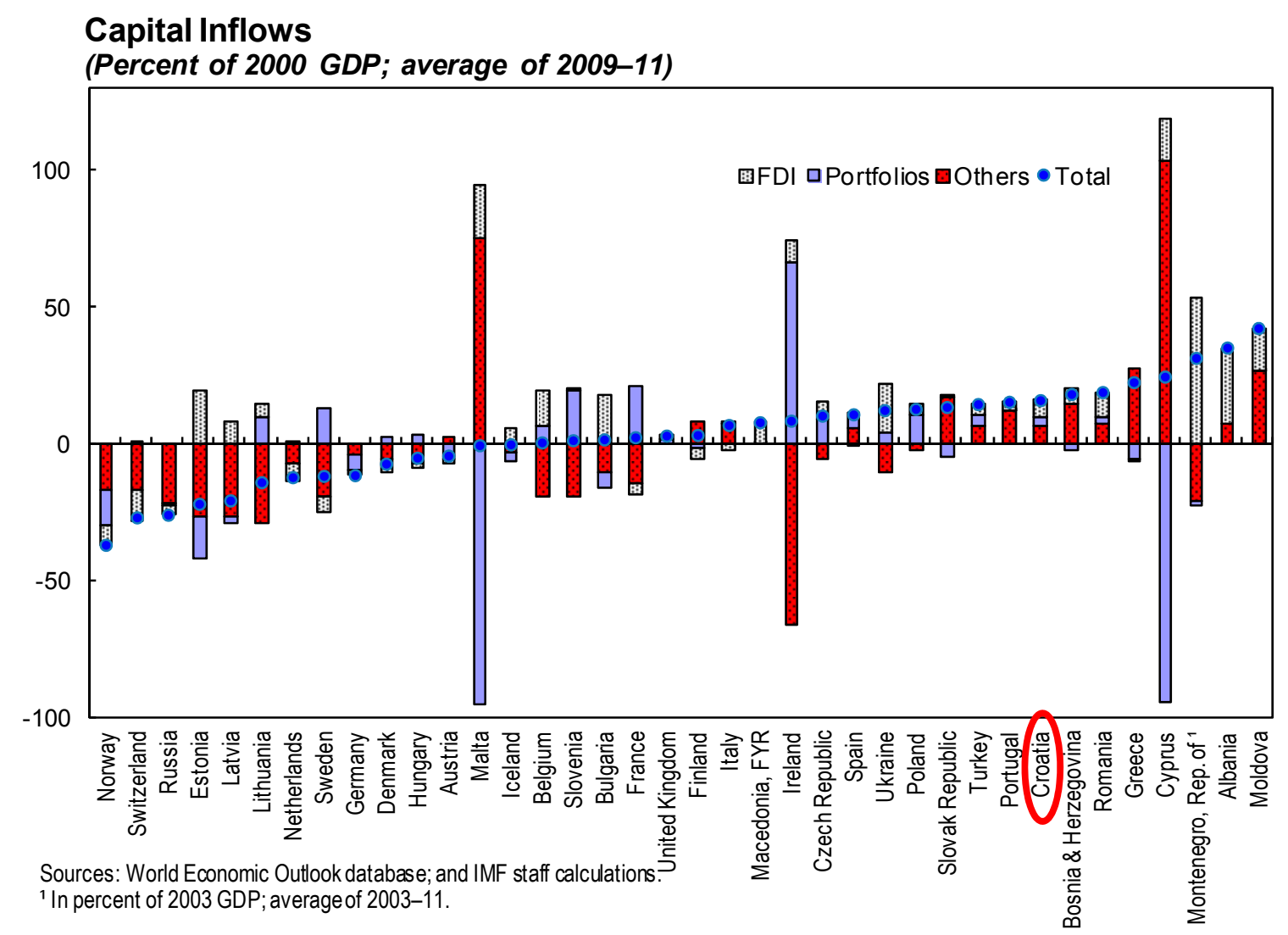

\section{Policy recommendations for Croatia based on the growth diagnostic}

26. The analysis shows that Croatia's binding constraints for growth have evolved over time. Before the crisis the level of investment was not a constraint for Croatia's growth, as it was able to attract high foreign capital flows. Rather, the poor allocation of capital towards non-tradable and low productivity sectors is likely to have been a drag on growth performance. Since the crisis, the deficiencies of Croatia's economic model and policies, combined with limited and more costly financing have given rise to elevated risks that lower perceived returns on investment in Croatia and have thus emerged as key constraints for growth.

27. While there is not much to be done to influence global risk aversion, a credible and sustainable fiscal consolidation would help. It would reduce Croatia's vulnerabilities and therefore lower the cost and improve availability of financing. Also, lower public deficit would reduce the risk of crowding out private investment and allow a reduction of the tax burden on labor, thereby improving Croatia's attractiveness to foreign investors.

28. In addition, several other policies could be implemented to raise the returns on investing in Croatia's tradable sector and help rebalance the economy. These include measures to: 
- Improve business environment and Croatia's attractiveness by easing regulatory obstacles to business, improving the judicial system, and increasing the efficiency of the public administration.

- Improve competition and productivity via faster restructuring and privatization of loss-making state-owned enterprises and reduction of subsidies to agriculture and other loss-making sectors.

- $\quad$ Increase labor market flexibility by easing labor markets regulations and reducing insider protection. More flexibility in setting wage contracts and lower hiring and firing costs will induce more competitive wage setting and raise the profitability of investment in tradable sectors.

\section{The Standard Reform Package or "Washington Consensus"}

29. The policy recommendations outlined above could be compared with the set of policy prescriptions aimed at promoting growth that form the core of IMF's and World Bank's usual policy advice. This reform package is often referred to as the "Washington Consensus", as termed by the economist John Williamson in 1989. While the "Washington Consensus" has evolved over time, in a learning-by-doing mode, it essentially relies on three main ideas: liberalization, privatization, and deregulation.

30. Croatia performs well on liberalization. Croatia is already a market economy, open to trade and therefore ranks high in the EBRD transition indicator for price, trade, foreign exchange, bank and interest rate liberalization.

\section{Croatia is however lagging in terms of large-scale privatization, enterprise} restructuring, infrastructure reforms and competition policy (text chart). While some progress has been recorded on competition policy (due to improvement in law enforcement and further strengthening of the competition law), no progress was made since 2008 in the other three items, highlighting the stalling of the structural reform momentum. Privatization has only seen very slow progress in recent years with the portfolio of state-owned companies still comprising about 645 companies, most of them highly indebted and loss-making, and no clear strategy to deal with them. The lack of progress is also particularly notable for the railway sector, which cannot survive without substantial state subsidies and is uncompetitive compared to other European companies owing to low traffic intensity, low staff productivity, high operating costs, and outdated infrastructure. Despite liberalization since 2008, Croatia's electricity and gas markets are still dominated by monopolistic suppliers. 
Croatia: EBRD transition indicators, 2000-2010

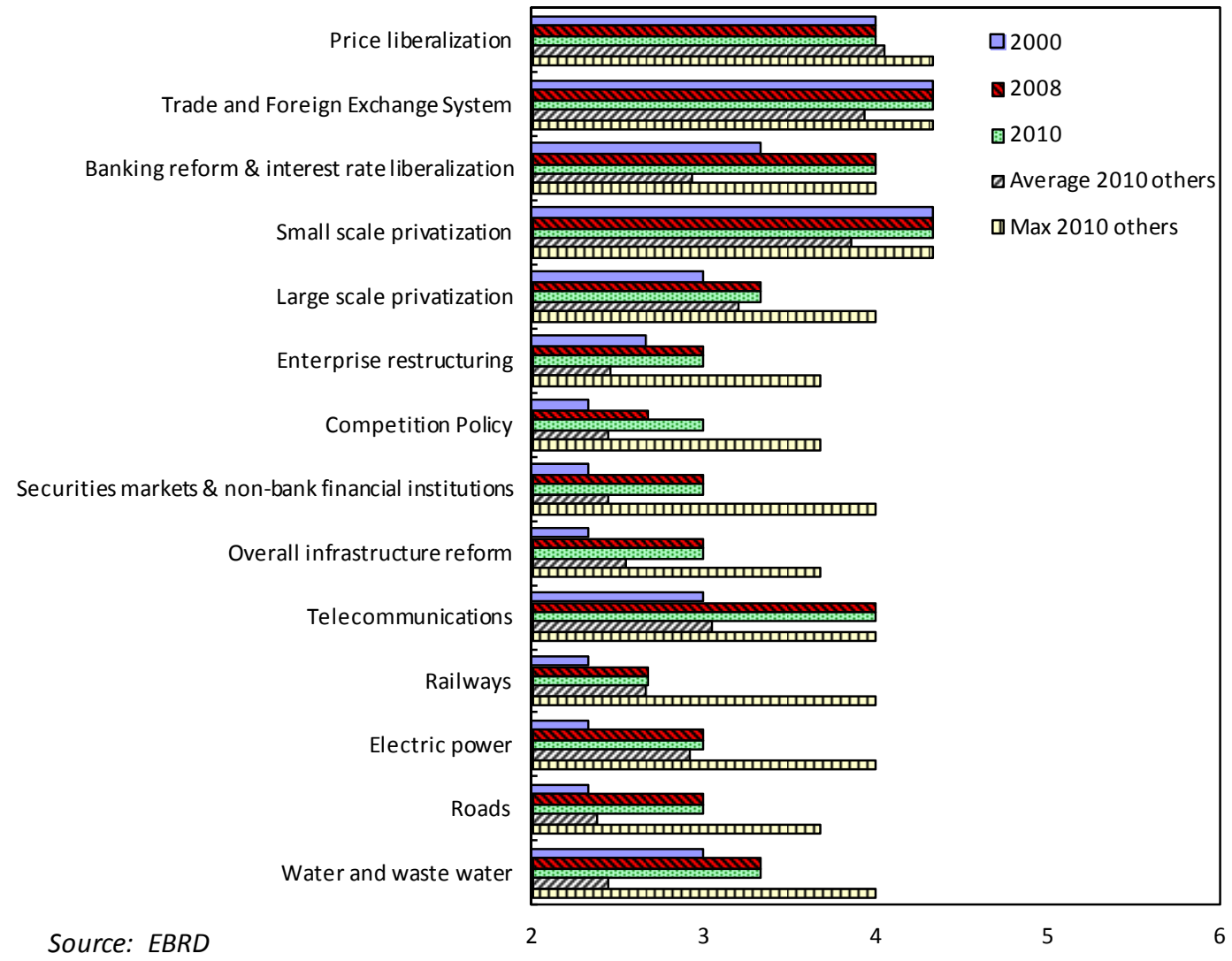

32. As a result, the standard policy recommendations for Croatia would focus on policies aimed at:

- Accelerating privatization and restructuring of state-owned companies;

- Increasing labor market flexibility and easing labor tax burden;

- $\quad$ Easing regulatory obstacles to business and strengthening competition.

\section{E. Reform Priorities in Croatia}

33. Interestingly, the policy prescriptions from the three approaches reviewed are very similar. They evolve around three themes: (i) increase work incentives to boost labor force participation and improve labor market flexibility; (ii) improve business environment and foster competition; and (iii) consolidate government finances to reduce macroeconomic risks that deter investment. These reform priorities are in line with the structural indicators of competitiveness, which point to these issues as the most problematic obstacles for doing business and investing in Croatia. 


\section{Reforming Croatia's labor market should aim at increasing both supply and demand of labor.}

- $\quad$ Reforms should aim at enhancing work incentives. While the government has taken some measures to increase labor force participation (via reduced possibilities and incentives for early retirement, gradual increase in retirement age for women, reform of the unemployment benefits, and better control of sick leave), they are unlikely to be sufficient. Notably, half of the planned increase in women retirement age will be compensated by the regular ageing process. A faster increase in the retirement age for women (for instance by 6 months per year rather than the 3 months per year decided in 2010) to 65 and a further increase to 67 for all would help offset the impact of ageing and boost labor supply (in addition to reducing the deficit of the pension system). In addition, early retirement incentives remain too high. The penalty for early retirement (1.8 percent per year) is below the actuarially neutral level of 3-4 percent and should be increased to at least that level. Hungary, Spain and Italy have for instance a penalty of 5-6 percent per year. Also, reducing the tax exemption level for pension income to that of regular wage income would eliminate a distortion in favor of early retirement.

- Measures should also be taken to reduce the tax burden on labor. The reduction of health contributions by 2 percentage points (with its revenue impact offset by an increase in VAT) in 2012, a so-called fiscal devaluation, is a step in the right direction and should help boost the demand for labor. The government could also consider increasing the zero VAT tax rate (which is not compatible with EU laws) to the 10 percent reduced rate (rather than 5 percent as currently envisaged). This would allow a further reduction in labor taxation. Raising property taxes could also help rebalance the tax structure away from labor in a revenue-neutral way, although the proceeds of such tax is likely to be low in the short-term given the need to first improve the land and property register.

- Several changes in the Labor Law would reduce the hiring and firing costs, and notably: (i) relax the conditions for dismissal, notably for poor performance, for collective dismissal and for some categories of protected workers in case of justified business reasons; (ii) allow firms to opt out from onerous sector-level collective agreements; and (iii) decrease the maximum amount of compensation paid to a wrongfully dismissed worker from the current 18 months of salary to a more affordable 6 months. 


\begin{tabular}{|c|c|c|c|c|}
\hline \multicolumn{5}{|c|}{ Table 1. Croatia Doing Business Indicators } \\
\hline Areas & Measures & $\begin{array}{c}2012 \text { as a } \\
\text { percent of } \\
2005 \\
\end{array}$ & $\begin{array}{c}\text { Croatia as a } \\
\text { percent of } \\
\text { the regional } \\
\text { average, } \\
2012\end{array}$ & $\begin{array}{c}\text { Croatia's as } \\
\text { a percent of } \\
\text { OECD } \\
\text { average, } \\
2012\end{array}$ \\
\hline \multirow[t]{4}{*}{ Starting a Business } & Number of procedures & 54.5 & 100.8 & 113.4 \\
\hline & Days required & 24.1 & 43.0 & 56.2 \\
\hline & Cost as a share of income per capita & 52.8 & 103.9 & 184.1 \\
\hline & Paid in minimum capital as a share of income per capita & 54.1 & 128.4 & 97.9 \\
\hline \multirow{3}{*}{$\begin{array}{l}\text { Dealing with construction } \\
\text { Permits }{ }^{1}\end{array}$} & \multirow{3}{*}{$\begin{array}{l}\text { Number of procedures } \\
\text { Days required } \\
\text { Cost (\% of income per capita) } \\
\end{array}$} & 52.2 & 56.7 & 86.9 \\
\hline & & 81.3 & 148.2 & 208.7 \\
\hline & & 60.6 & 124.7 & 1293.6 \\
\hline \multirow[t]{3}{*}{ Registering property } & \multirow{3}{*}{$\begin{array}{l}\text { Number of procedures } \\
\text { Days required } \\
\text { Cost (as a \% of property value) }\end{array}$} & 100.0 & 88.2 & 104.0 \\
\hline & & 10.9 & 348.9 & 339.4 \\
\hline & & 100.0 & 213.4 & 114.5 \\
\hline \multirow[t]{4}{*}{ Protecting Investors ${ }^{1}$} & Extent of disclosure index $(0-10)$ & 100.0 & 14.5 & 16.4 \\
\hline & Extent of director liability index $(0-10)$ & 100.0 & 119.3 & 97.5 \\
\hline & Ease of shareholder suits index (0-10) & 100.0 & 98.4 & 89.0 \\
\hline & Strength of investor protection index (0-10) & 100.0 & 69.7 & 66.8 \\
\hline \multirow[t]{6}{*}{ Trading across Borders ${ }^{1}$} & Documents to export (number) & 100.0 & 99.3 & 160.7 \\
\hline & Days required to export & 76.9 & 68.7 & 191.4 \\
\hline & Cost to export (US\$ per container) & 108.3 & 68.4 & 126.0 \\
\hline & Documents to import (number) & 100.0 & 100.6 & 165.3 \\
\hline & Days required to import & 88.9 & 51.0 & 148.9 \\
\hline & Cost to import (US\$ per container) & 98.3 & 55.2 & 108.8 \\
\hline \multirow[t]{3}{*}{ Enforcing Contracts } & Number of procedures & 100.0 & 101.4 & 120.9 \\
\hline & Days required & 100.0 & 143.4 & 108.3 \\
\hline & Cost (\% of claim) & 100.0 & 48.1 & 70.0 \\
\hline \multirow[t]{3}{*}{ Resolving insolvency } & Recovery rate (cents on the dollar) & 103.1 & 88.8 & 43.6 \\
\hline & Years required & 100.0 & 112.2 & 179.3 \\
\hline & Cost (\% of estate) & 100.0 & 119.3 & 164.9 \\
\hline
\end{tabular}

1. Percent of 2006

Source: Doing Business report 2012, World Bank

\section{Reforms to improve the business environment should aim at improving the legal}

and regulatory framework in order to increase investment. While some progress has been made since 2005, the time and costs of the procedures for dealing with construction permits and property registration remain significantly above the levels in Croatia's peers. It is the time to register the new construction or property in the Land Registry that accounts for the longest delay (respectively 120 and 60/80 days). The planned digitalization and update of the land registry and cadastre should therefore be accelerated. Barriers to investment at the local government level should also be removed. Rules regarding the disclosure of conflict of interest as well as investor protection should also be improved. It is also urgent to strengthen the insolvency procedures and fasten the enforcement of judicial decisions. It takes about 50 percent more time to enforce a contract in Croatia compared to its peers due to long delay in the judicial system, while resolving insolvency takes about twice the time than in the OECD countries and the recovery rate is low (see Table 1). According to the 2011-2012 Global 
competitiveness report, the inefficient government bureaucracy is the most problematic factor for doing business in Croatia, while Croatia's ranking in terms of the quality of its legal framework, protection of investors and minority shareholders and burden of regulation is at the very end of the index (111-137 out of 142) (Appendix Figure 6B).

36. More rapid privatization and enterprise restructuring would help foster competition. Privatization plans should be accelerated, including for the still unresolved shipyard companies, and a clear strategy put forward for liquidating or selling the assets owned by the Asset Management Agency. The launching of the restructuring of the railways company is welcomed and should be pursued further, while the electricity and gas markets should be liberalized further.

37. Fiscal consolidation efforts will need to be continued in the medium-term. Sustained fiscal consolidation will help improve the access and cost of financing both for public and private entities and will facilitate a reduction of the tax burden on labor, thereby encouraging higher investment.

38. Further efforts should be applied to raise government efficiency. The government's intention to tackle corruption and implement a fiscal consolidation will help reduce wasteful and inefficient government spending. Government efficiency could be further improved by: (i) a rationalization of the structure of government operations, involving a comprehensive functional review of the size, functions and staffing of all government organizations; (ii) a reform of the salary formula to establish a tighter link between performance and salary, eliminate the seniority bonus and align wages at all levels of government; (iii) outsource non-core functions, such as transport, security, mail, cleaning, catering and maintenance to improve efficiency and generate fiscal savings.

\section{F. Possible Impact of the Reforms}

39. Quantifying the impact of structural reforms on growth is far from trivial. Most empirical studies find a positive long-term effect of labor and product market reforms on total factor productivity, growth and employment. However, the impact of the reforms varies widely as it depends on their specifics, the interactions between product and labor market institutions, the macroeconomic environment in which the reforms take place, and the timeframe as short-term effects may be smaller or even negative due to the cost and time of resources relocation and restructuring.

40. Calculations based on the growth accounting exercise conducted in Section A suggest that increasing participation rate and employment rate could help to lift GDP growth substantially. If Croatia's participation rate were to increase in the next eight years 
to 70 percent as in the Czech Republic, GDP growth would increase by about 1 percent. This would in turn require an increase in investment to GDP ratio by 1 percentage point ${ }^{9}$.

\section{Growth regressions show that in Croatia, structural reforms have the potential} to increase economic growth significantly by improving productivity. Using the model in Vamvakidis (2008), increasing the economic freedom index to the level of Estonia (the best performer in emerging Europe) over the next five years would boost average annual growth by 0.9 percentage points. ${ }^{10}$ Reaching the average level of eastern European countries would boost growth by close to 0.4 percentage points. This would be mainly achieved by improving labor market flexibility and the efficiency of the legal framework and government spending, the areas where Croatia ranks the lowest. Moore and Vamvakidis (2007) ${ }^{11}$ who have estimated a growth model for Croatia also show that improving the economic freedom index and the cost of starting new business to the average level of CEE countries, the euro area, or Ireland would increase average annual growth by about $0.4,0.5$, and 0.8 percentage points, respectively.

42. In addition, the impact of these reforms would be magnified by their impact on investment and FDI. If the investment to GDP ratio is increased from its current level of close to 22 percent to 25 percent $^{12}$ (the minimum level according to the Spence Report and also the average level in Slovakia, Slovenia, Czech Republic, Bosnia, Latvia in 2000-08), possibly through attracting more FDI, this would boost annual GDP growth by an additional 0.3 percentage points (the models in Vamvakidis (2008) and Moore and Vamvakidis (2007) give similar results).

\footnotetext{
${ }^{9}$ Assuming that the unemployment rate would remain broadly the same, this scenario would imply an increase in employment by about 19 percent. Assuming a constant capital to labor ratio, this would require an average increase of the capital stock by 2.2 percent per year, leading to an increase in investment to GDP ratio by 1 percentage point over these years.

${ }^{10}$ The specification of his model is Real per capita GDP growth $=11.00-1.38 *(\log$ per capita GDP $)-$ $7.05 *$ (age dependency rate) $+0.13 *$ (investment to GDP ratio) $+0.02 *$ (university enrollment ratio) $0.015 *($ inflation rate $)+0.07 *($ FDI ratio $)+0.59 *($ economic freedom $)+0.86 *($ change in economic freedom $)$.

11 The specification of this model is Real GDP per capita growth $=0.98+1.88 *$ (dummy for SEE and CEE) $0.49 *$ (initial real GDP per capita) $-0.43 *$ (population growth) $+0.14 *$ (investment to GDP ratio) $0.02 *($ inflation rate $)+0.001 *($ credit to private sector/GDP $)+0.43 *($ index of economic freedom $)-0.03 *(\operatorname{cost}$ of business start-up procedures in $\%$ of GNI per capita.

${ }^{12}$ Achieving such a level in 8 years would require an average annual increase in the capital stock by about 2.4 percent and an annual increase in gross fixed capital formation by about 3.4 percent. In this scenario, the capital stock would increase by about 21 percent after eight years. Depending on the capital intensity of output, this could potentially generate further employment growth (above the one implied by the 70 percent participation rate), and thus even higher GDP growth.
} 
43. The total impact of these reforms could be significant. While not all of these effects may be strictly additive and the quantification of the impact of structural reforms on growth is subject to large estimation errors, this exercise nevertheless suggests that the impact of structural reforms on GDP growth in Croatia could be substantial and exceed 2 percent in the medium to long-term.

\begin{tabular}{lc}
\hline \hline Impact on medium-term annual growth rate & \\
\hline Macroeconomic reforms & 1.4 \\
Higher participation rate (target: 70\%, as CZE) & 1.1 \\
o/w: Increase in employment growth & 1 \\
$\quad$ Increase in capital to keep K/L ratio constant & 0.1 \\
Higher domestic investment (from 23 to 25\% of GDP, as SVK, SVN, CZE, LVA) & 0.3 \\
Structural reforms (target: level of CEEC/EST) & $0.4-0.9$ \\
\hline Total effects & $\mathbf{1 . 8 - 2 . 3}$ \\
\hline \hline References: Vamvakidis (2008), Moore and Vamvakidis (2007)
\end{tabular}

\section{G. Conclusions}

44. Croatia's pre-crisis growth model relied on capital accumulation in the non-tradable sector, which led to low productivity gains and export growth compared to its peers. Achieving reasonable medium-term growth requires a fundamental change in the economic policies and institutions.

\section{The policy recommendations coming from the reviewed three sources of} economic thought are very similar. To boost medium-term growth, Croatia needs to (i) increase work incentives to boost labor force participation and improve labor market flexibility, which will help the economy regain competitiveness and support export-led growth; (ii) improve business environment, via easier regulations, better legal framework, and more efficient administration, and foster competition by accelerating privatization and enterprise restructuring, to attract capital to the tradable sectors and boost productivity; and (iii) continue the fiscal consolidation efforts in the medium term to reduce macroeconomic risks and improve the access and cost of financing. Empirical evidences suggest that the impact of those reforms could be quite substantial, raising annual GDP growth by about 2 percent in the medium to long term. 


\section{References}

Everaert L., and W. Schule, 2006, "Structural Reforms in the Euro Area: Economic Impact and Role of Synchronization Across Markets and Countries", IMF Working Paper No. 06/137 (Washington: International Monetary Fund).

Hausmann, R., Rodrik D., and Velasco A., 2005, “Growth Diagnostics”, Working Paper. Available via Internet: www.hks.harvard.edu/fs/rhausma/publication.htm.

International Bank of Reconstruction and Development (IBRD), 2008, "The Growth Report-Strategies for Sustained Growth and Inclusive Development" by the Commission on Growth and Development (Washington).

Goldman Sachs, 2012, “Our 2011 GES: A sharper Signal for Growth”, Goldman Sachs Global Economics, Commodities and Strategy Research.

Moore D. and Vamvakidis A., 2007, Economic Growth in Croatia: potential and constraints, IMF Working Paper No. 07/198 (Washington: International Monetary Fund).

Mourre G., 2009, "What Explains the Differences in Income and Labour Utilization and Drives Labour and Economic Growth in Europe? A GDP Accounting Perspective", Economic Papers 354, January 2008, European Economy, European Commission.

Organization for Economic Co-operation and Development, 2012, "OECD Economic Surveys Euro Area," (Paris).

Vamvakidis A., 2008, "Potential Growth Estimates in Emerging Europe Based on a Growth Model," Box 8 of Regional Economic Outlook: Europe, April (Washington: International Monetary Fund).

Schadler, S., Mody, A., Abiad, A.; Leigh, D., 2007, "Growth in Central and Eastern European Countries of the European Union," IMF Occasional Paper 252 (Washington: International Monetary Fund). 
APPENDiX

Figure 1. Croatia: Relative growth performance, 2000-2011
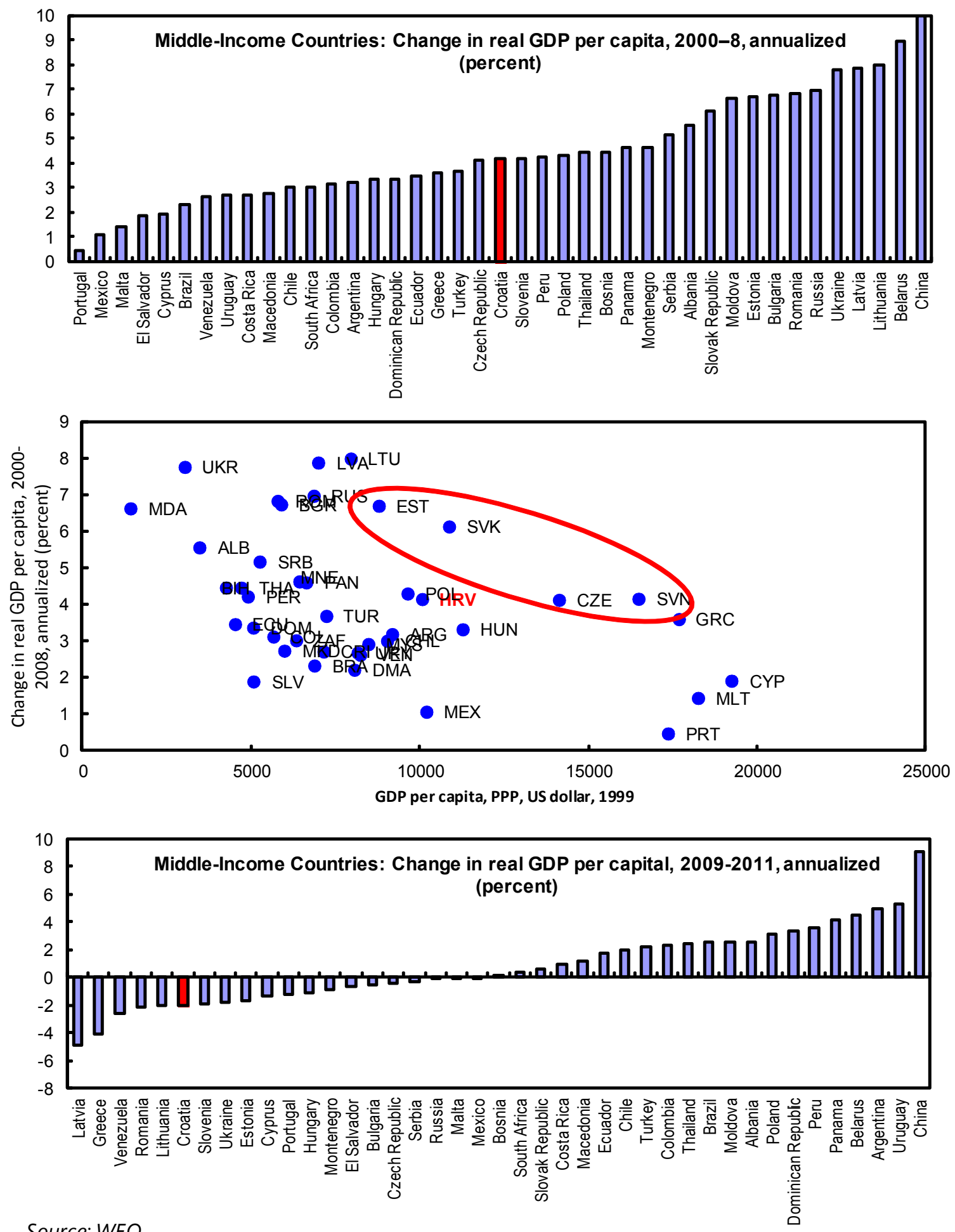

Source: WEO 
Figure 2A. Middle-Income Countries: Growth Accounting, 2000-08
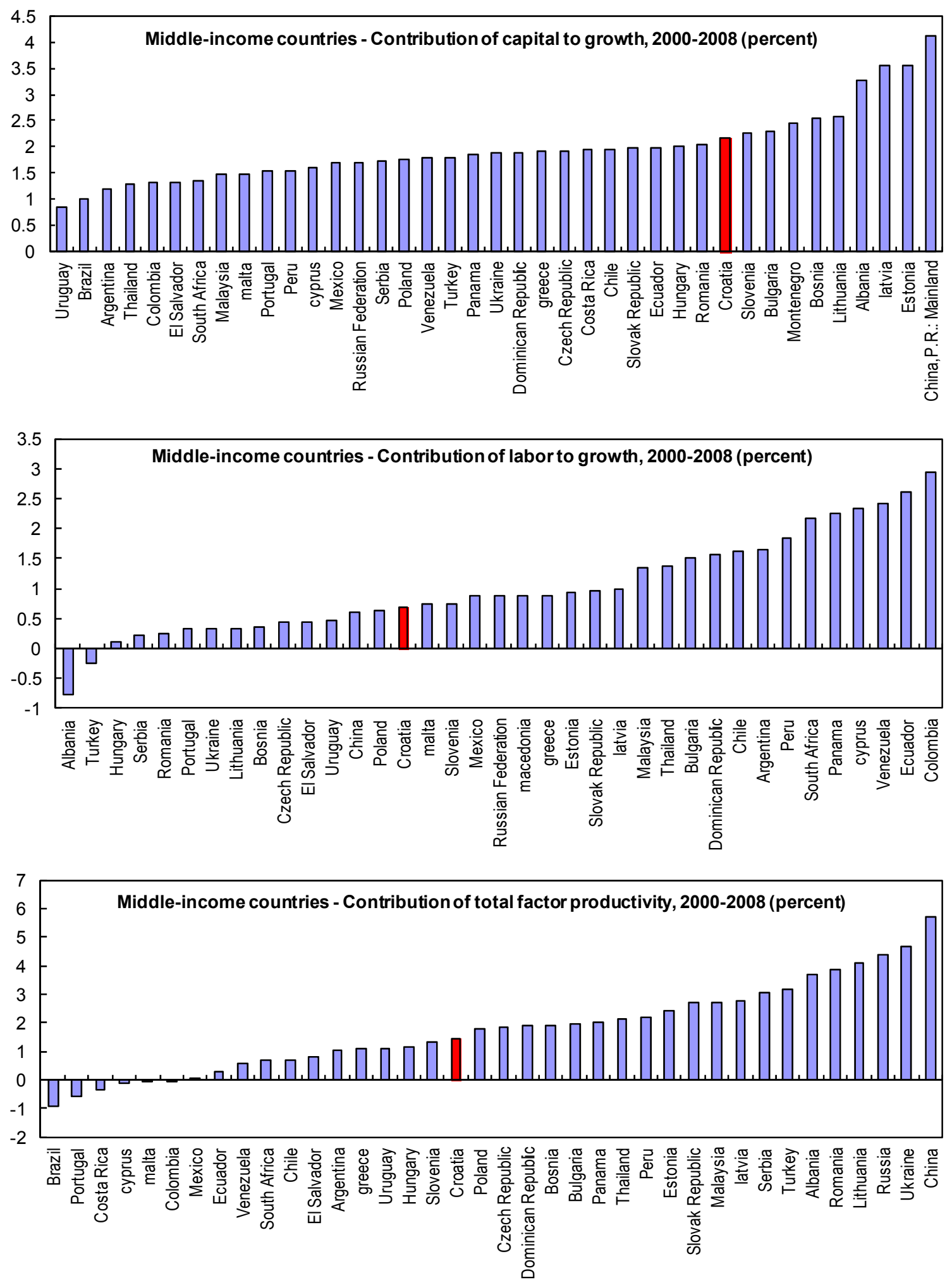

Source: WEO \& IMF Staff Computations 
Figure 2B. Middle-Income Countries: Growth Accounting, 2009-11
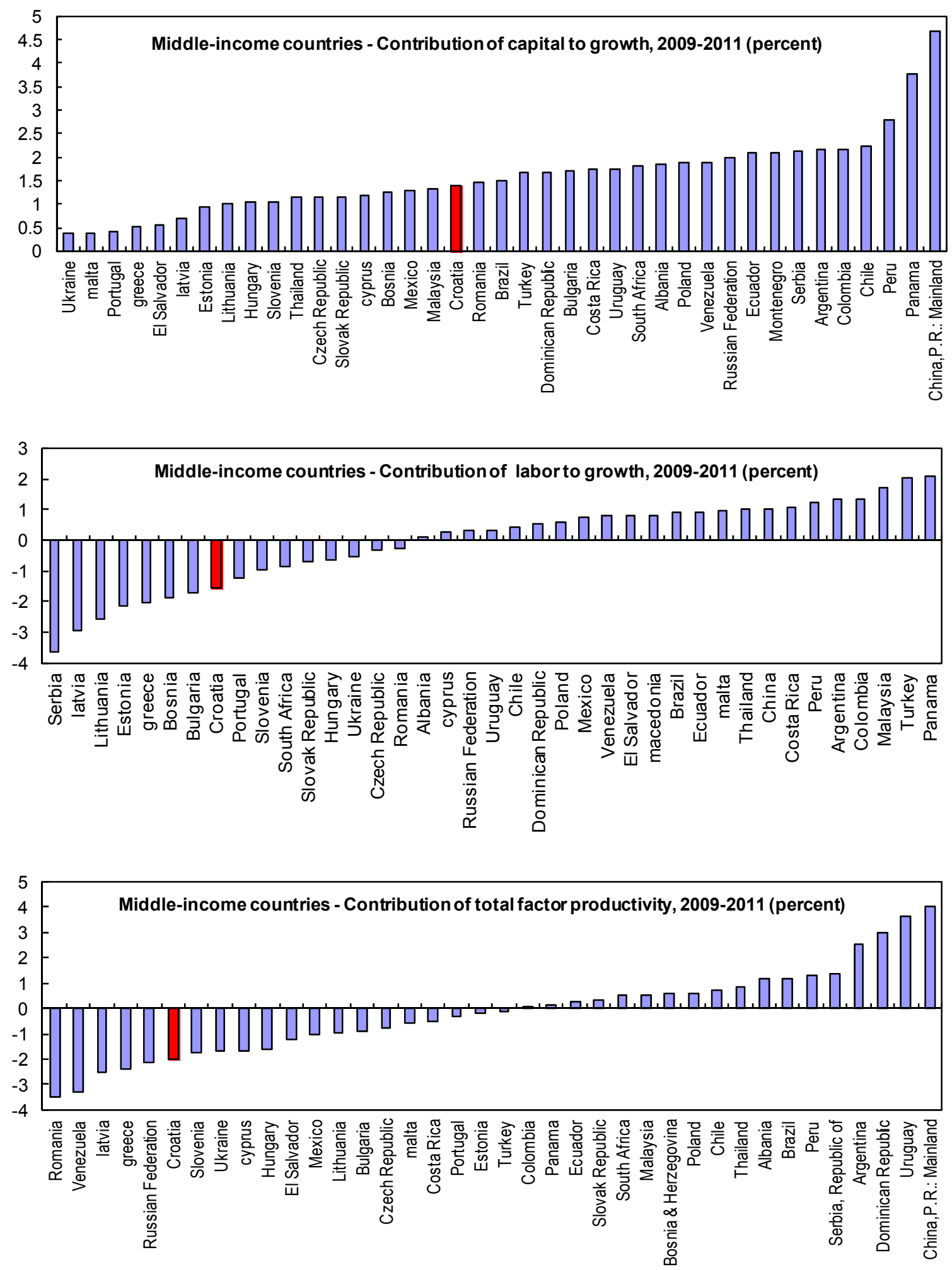

Source: WEO \& IMF Staff Computations 
Figure 3. Middle-Income Countries: Employment Growth Decomposition, 2000-11
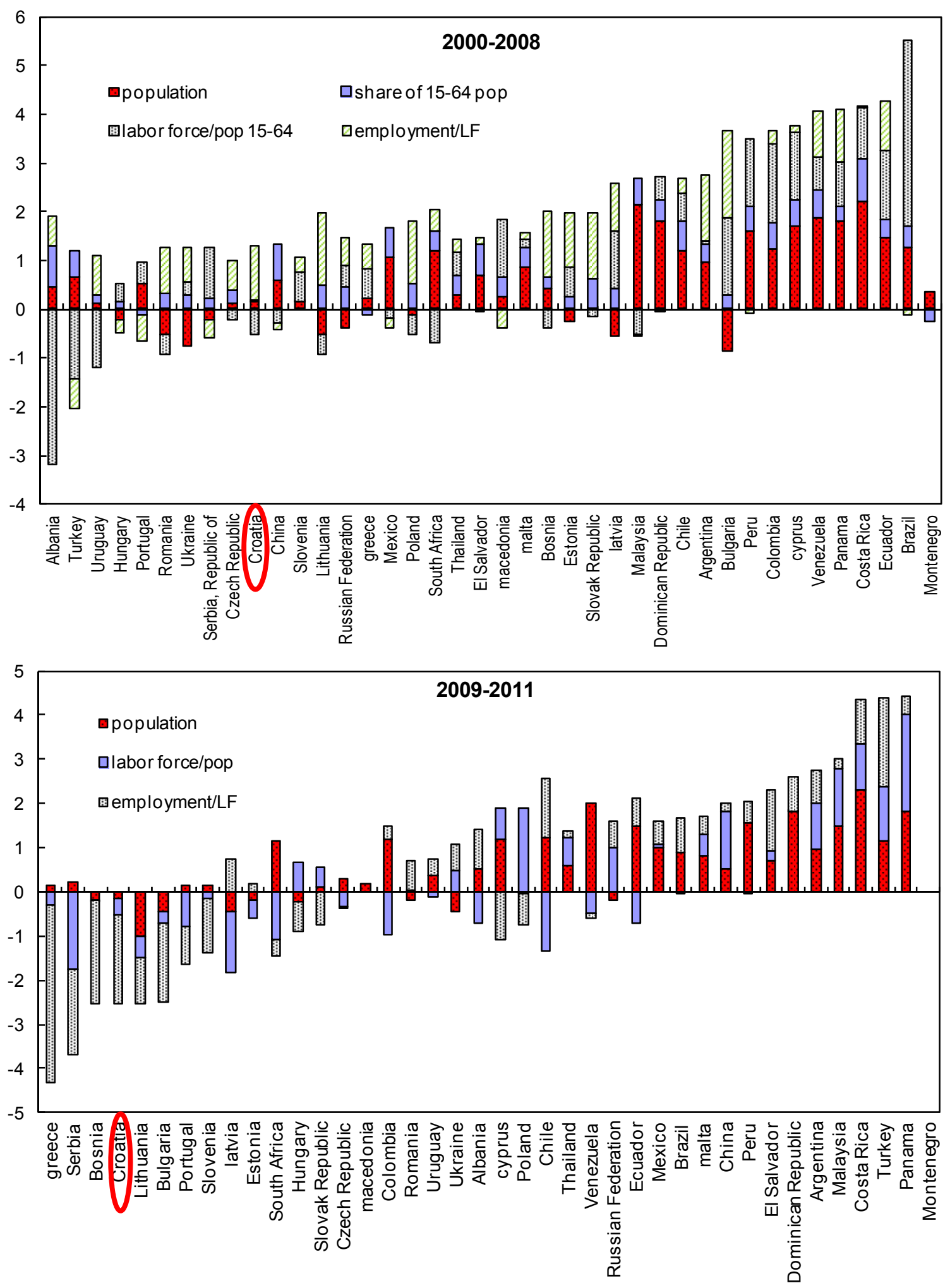

Source: WEO, World Bank WDI, IMF staff computations 
Figure 4. Croatia: Education Level of the Labor Force
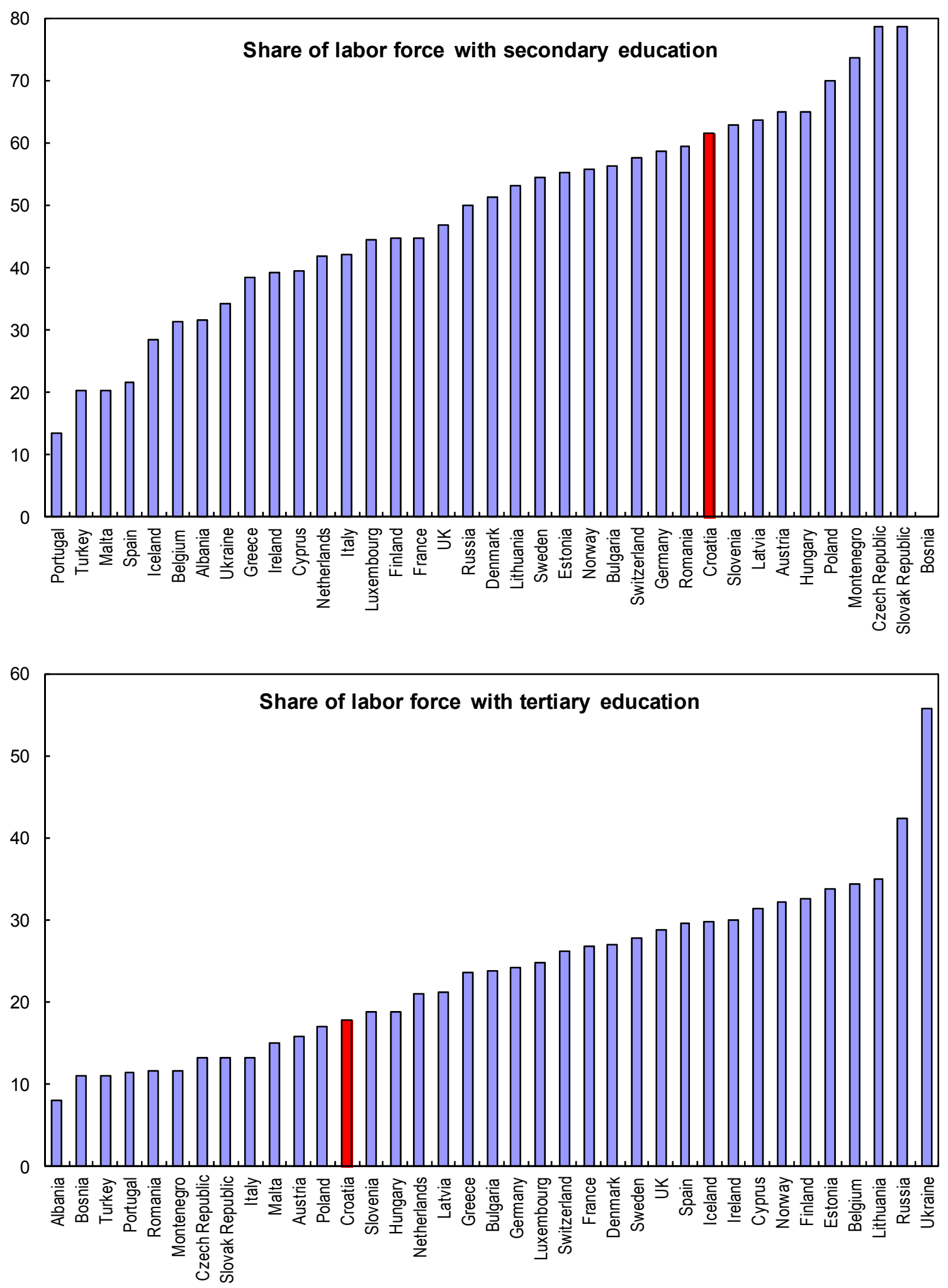

Source: Eurostat 
Figure 5. Croatia: Openness to the global economy
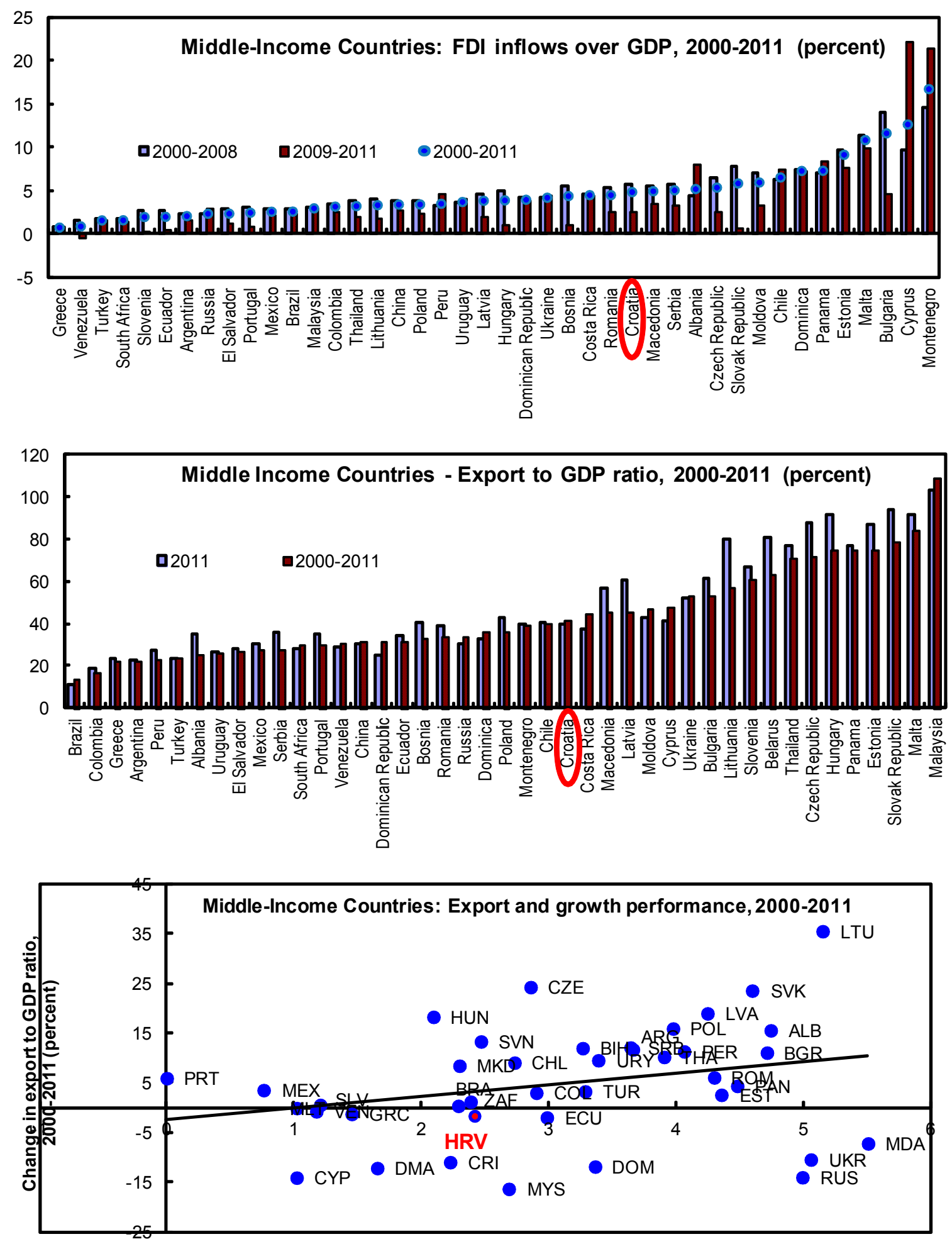

Change in real GDP per capita, 2000-2011, annualized (percent)

Source: WEO 
Figure 6A. Croatia: Business Environment, 2011-12
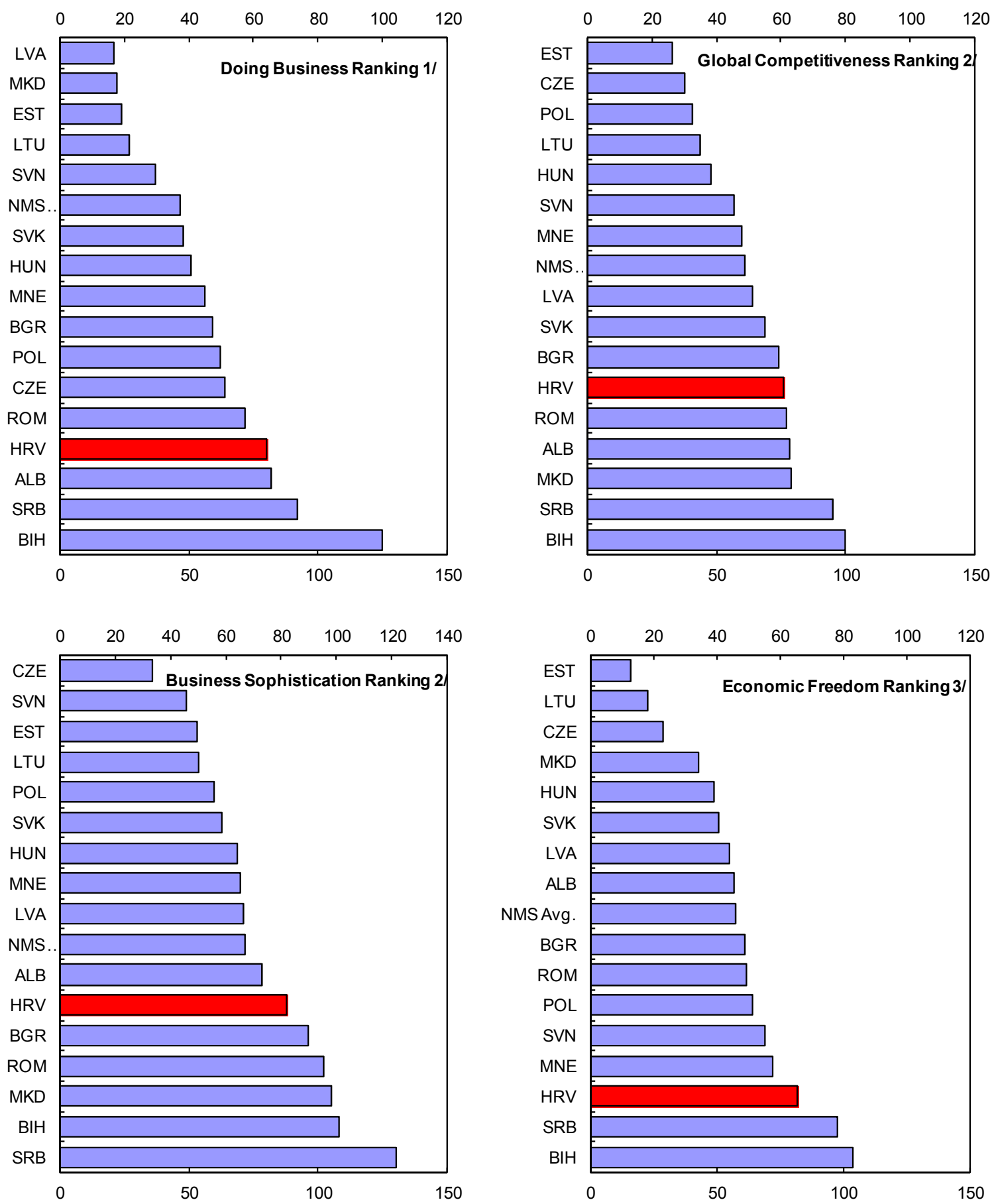

Sources: World Bank, Doing Business; World Economic Forum, Global Competitiveness Report; Heritage Foundation, Economic Freedom Index; and IMF staff calculations.

$1 /$ Covers the period June, 2010 through May, 2011. Rank out of 183 countries.

2/ Rank for 2011-12. Ranking out of 142 countries.

3/ Rank as of 2012. Ranking out of 184 countries. 
Figure 6B. Croatia: Business Environment, Components, 2005-2012

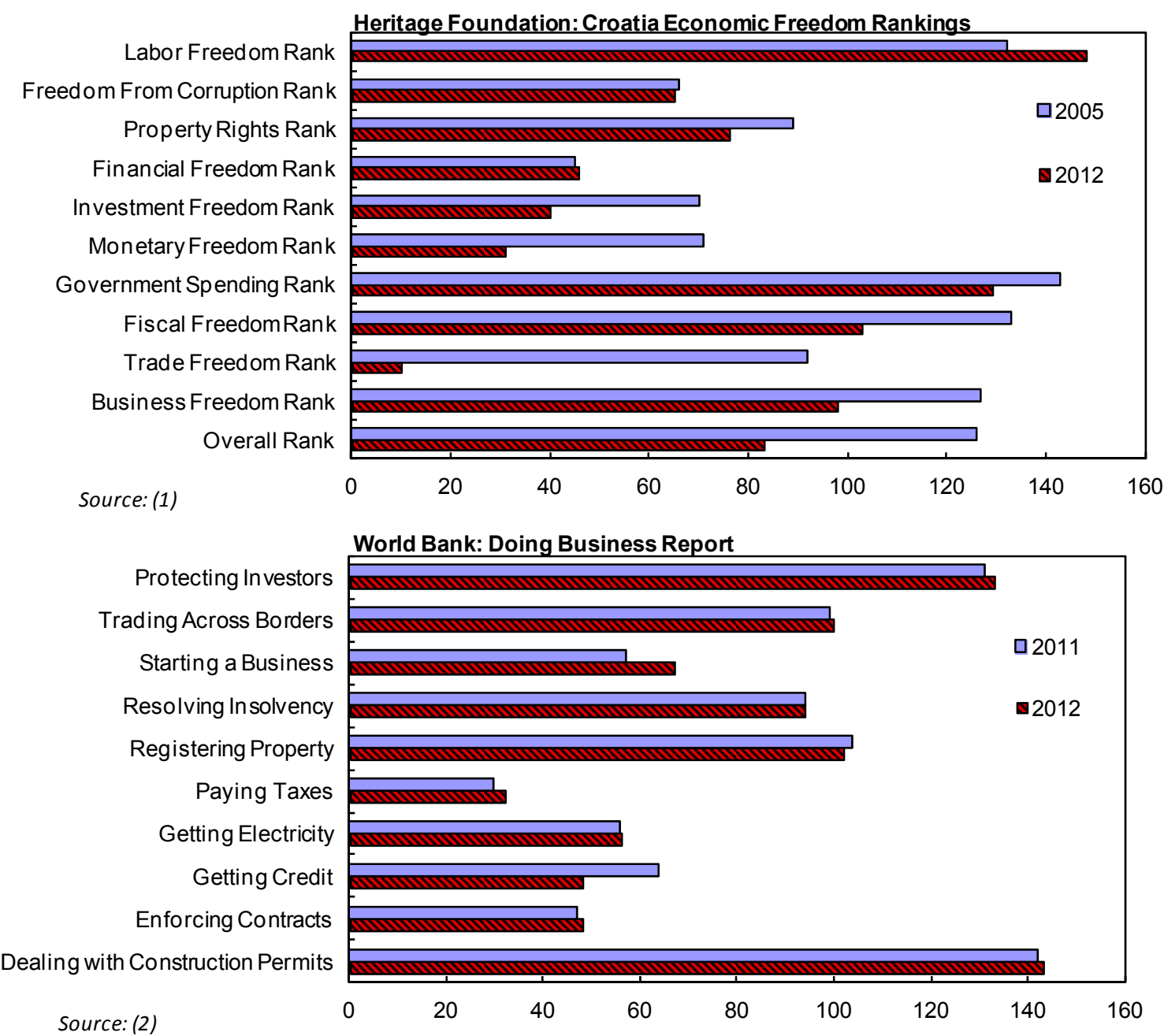

ource: $(2)$

\section{Global Competitiveness Rankings: Croatia}

Labor market efficiency Rank

Goods market efficiency Rank Institutions Rank

Business sophistication Rank Financial market development Rank Innovation Rank Market size Rank Macroeconomic en vironment Rank Higher ed ucation and training Rank Health and primary education Rank Infrastructure Rank

Technological readiness Rank

Source: (3)

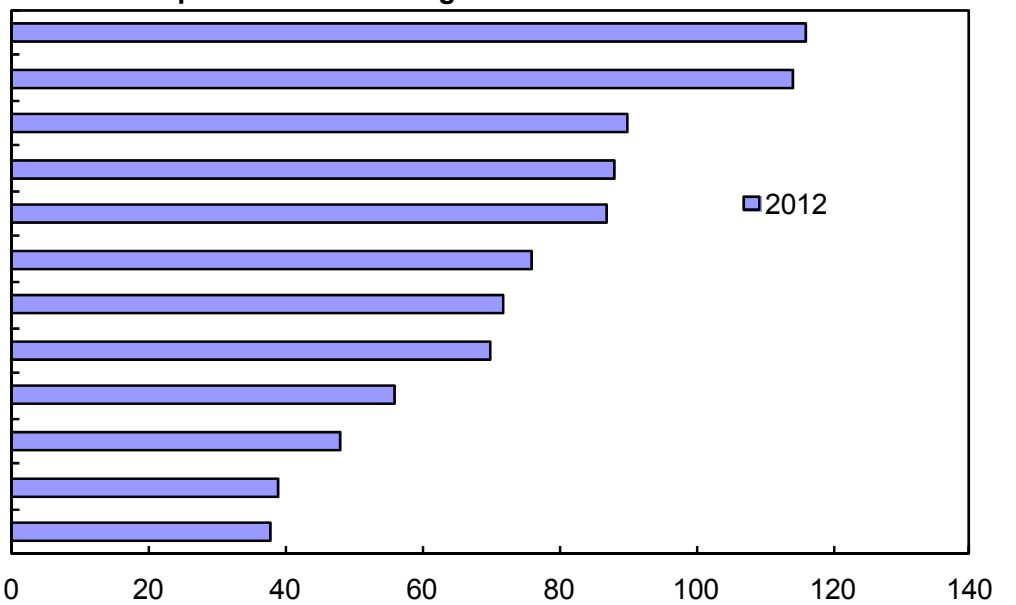

(1) Heritage Foundation Economic Freedom Index 2012, 2005; Rank: Out of 179 Countries, 1 = Best Score

(2) World Bank Doing Business Report 2011-12; Rank: Out of 188 Countries, 1 = Best Score

(3) Global Competitiveness Index Report 2011, 2012; Rank out of 142 Countries, 1 = Best Score 
Figure 7. Croatia: Access to international financing, 2000-2008
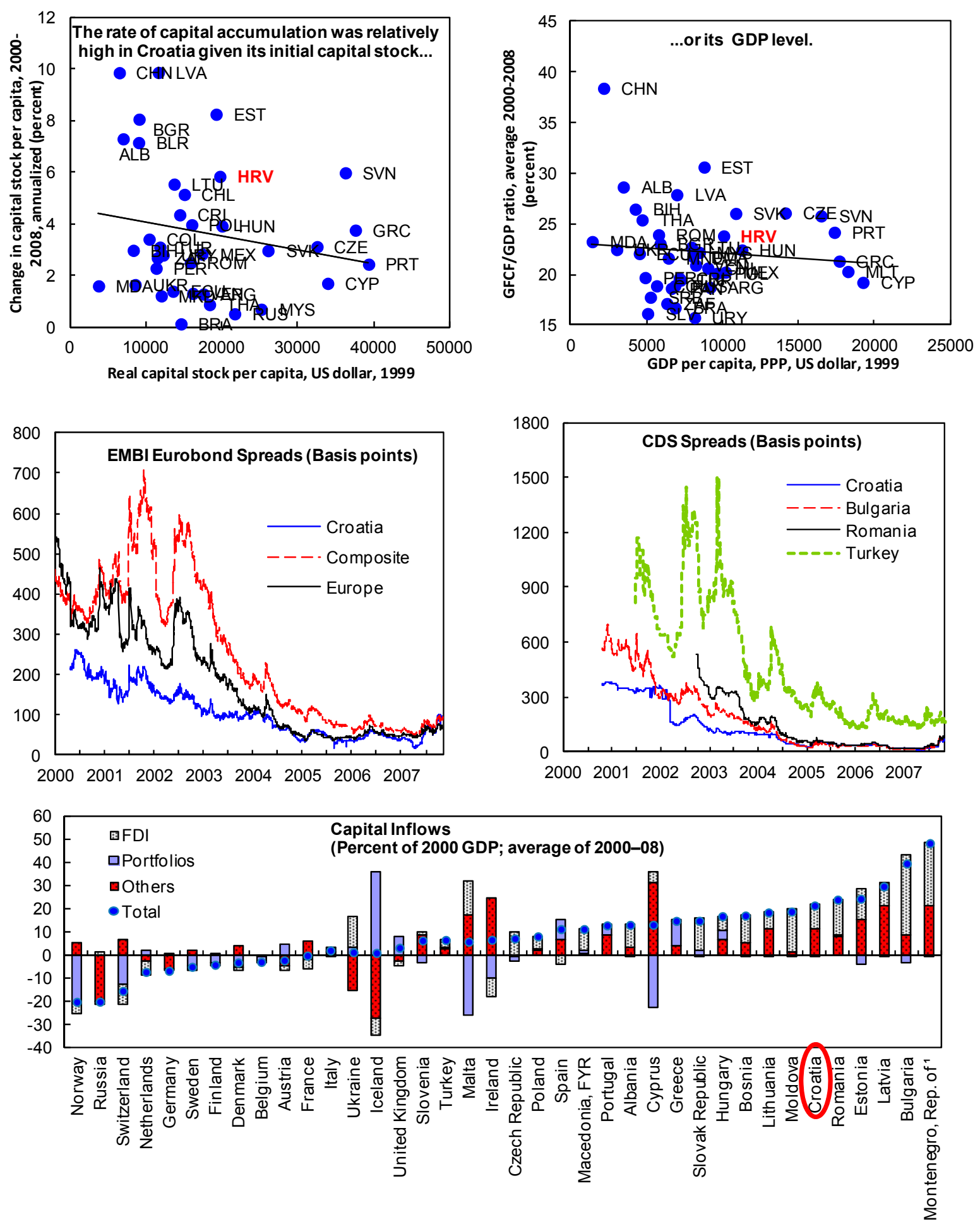

Source: Bloomberg;Penn Tables; World Economic Outlook database; and IMF staff calculations.

${ }^{1}$ In percent of 2003 GDP; average of 2003-10. 
Figure 8. Croatia: Access to domestic financing
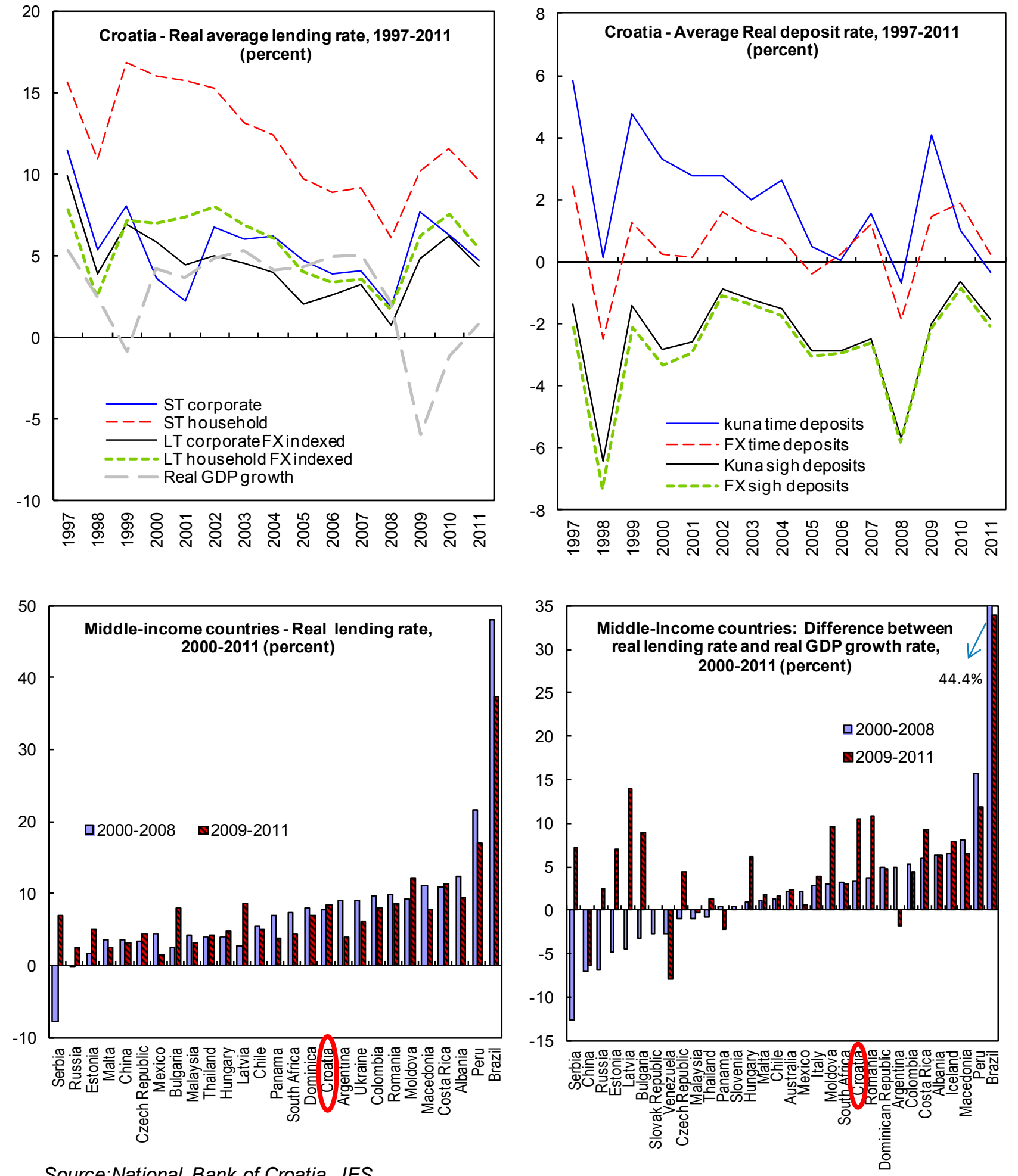

Source:National Bank of Croatia, IFS. 
Figure 9. Croatia and other Eastern European Countries: Structure of production by branches
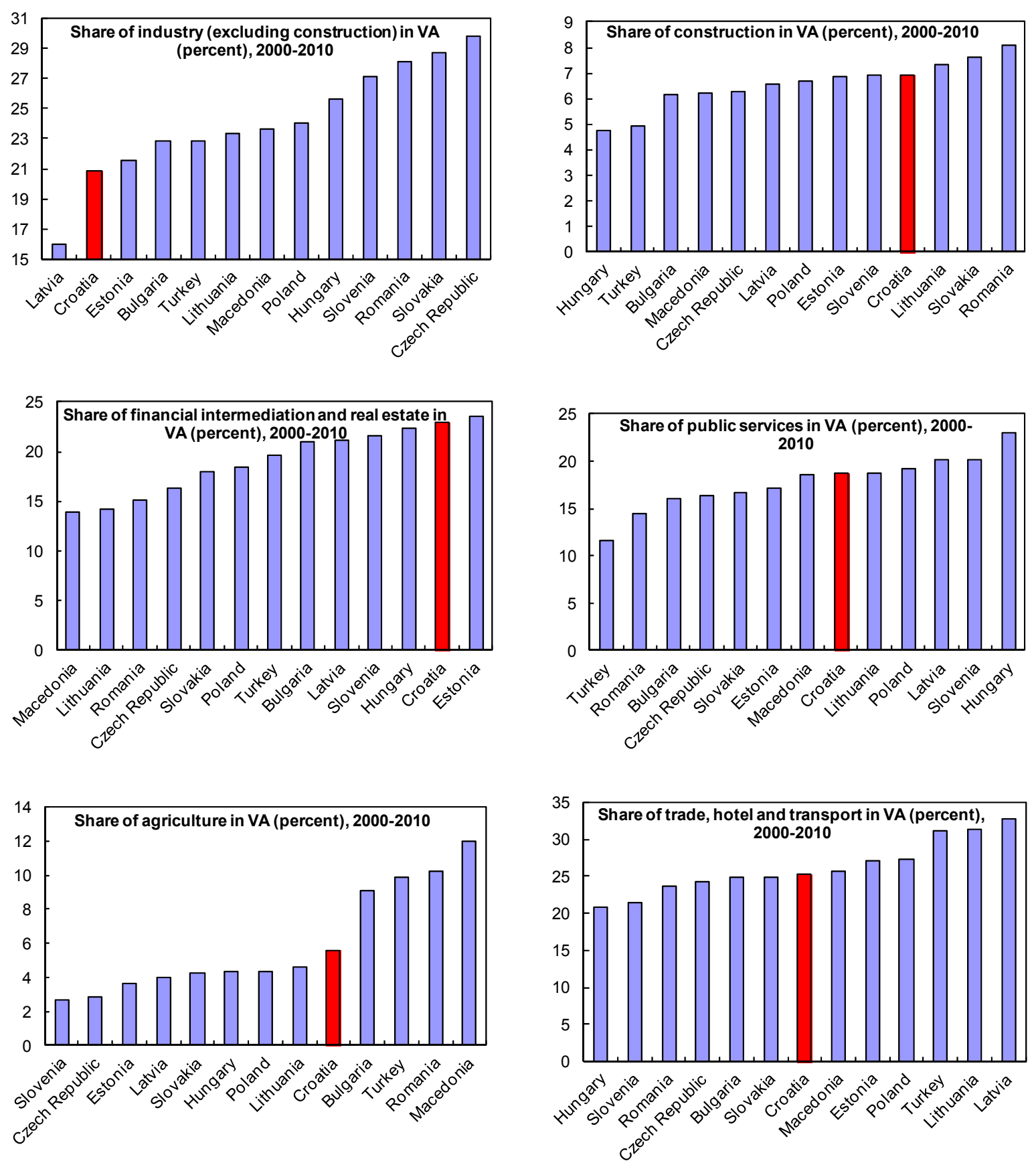

Source: Eurostat 
Figure 10. Croatia: Investment Structure ${ }^{1}$
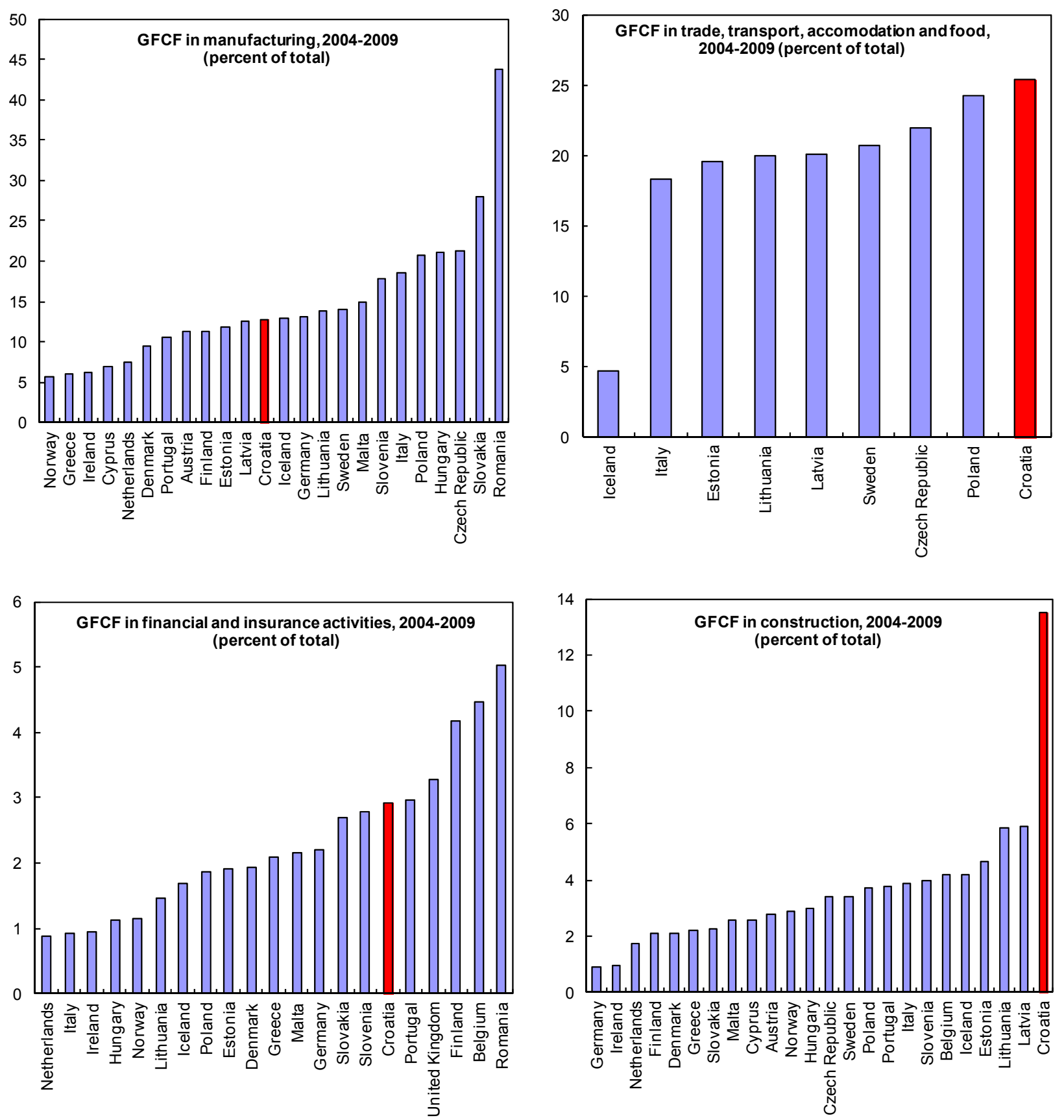

Source: Eurostat.

Investment is measured as Gross Fixed Capital Formation (GFCF) 
Figure 11. EU and US: Average TFP growth by sectors, 95-2007, annualized (percent)

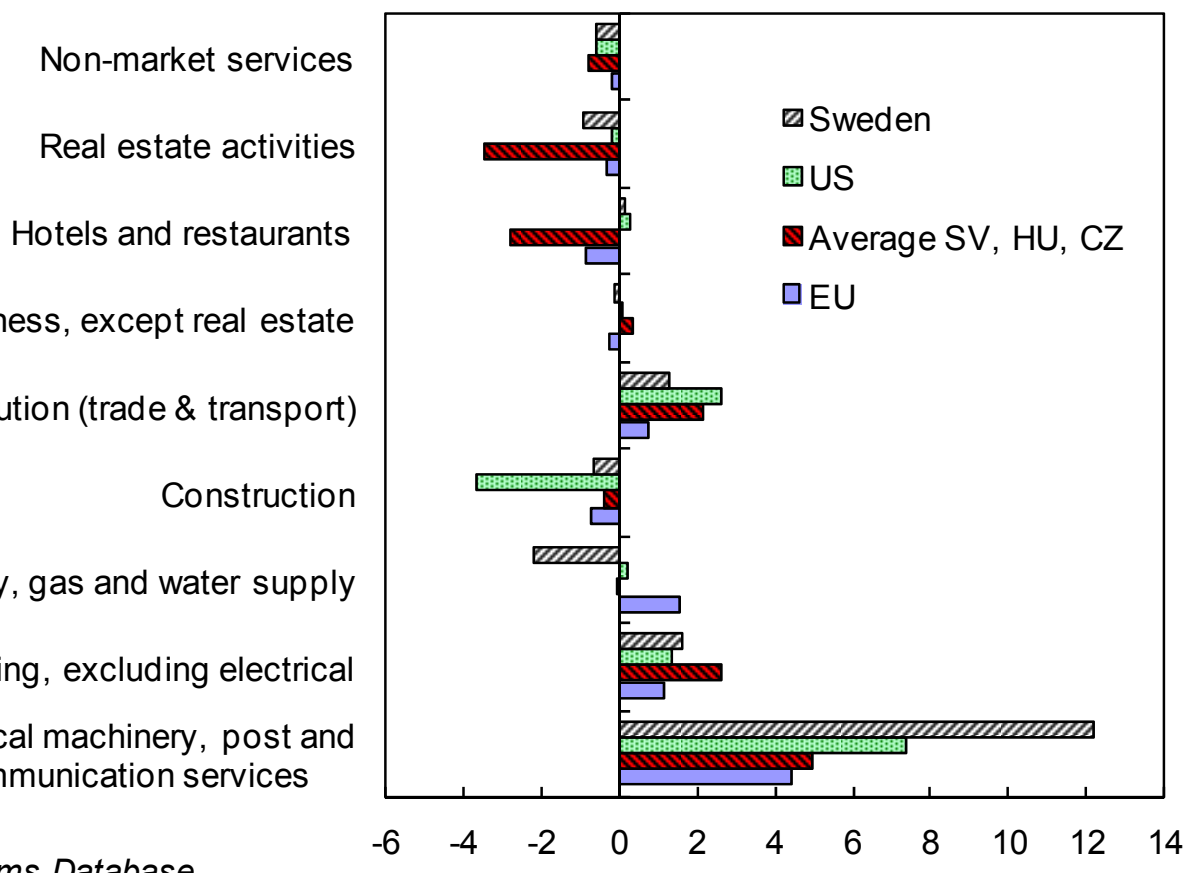

Source: EU Klems Database 
Figure 12. Croatia: Cost of Finance, 2008-2011
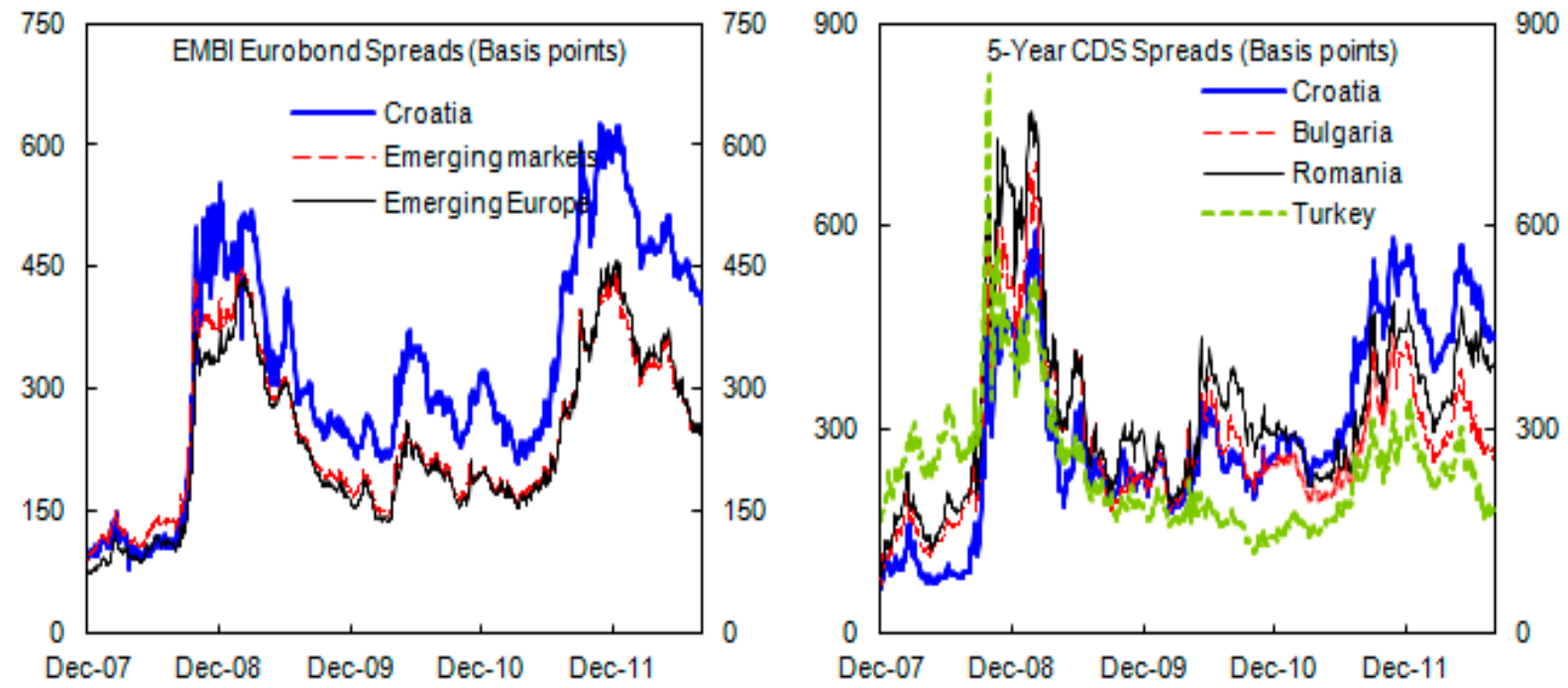

Source: Bloomberg.

Figure 13. Croatia: Innovation performance
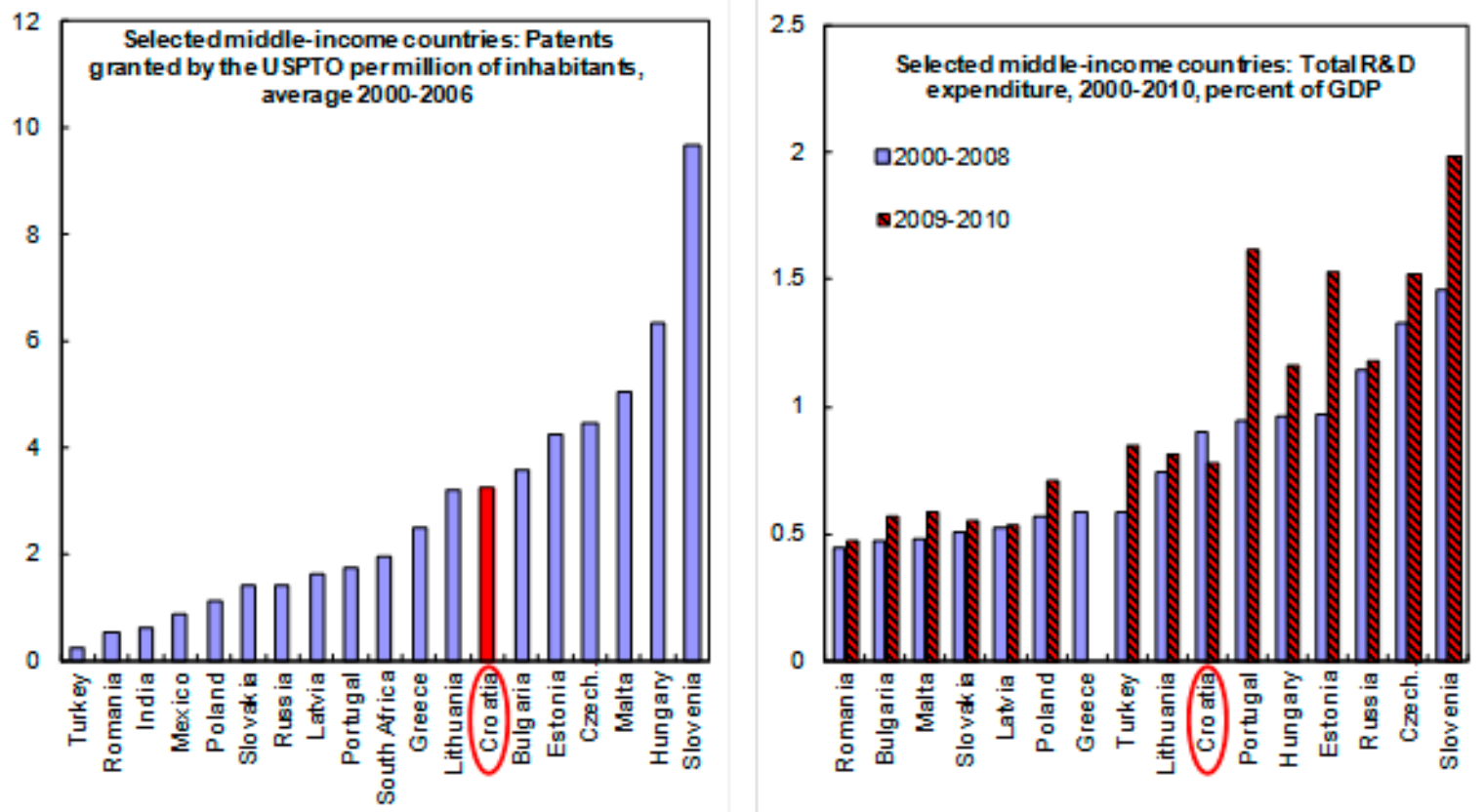

Source: Eurostat 


\section{Croatia-Export Performance, Wages, And Productivity ${ }^{1}$}

The note examines various price measures from a cross country perspective with specific focus on the link between productivity growth, wages and export performance. The result of this analysis suggests that Croatia's high wage level is a major drag on export performance. Disaggregated analysis of export products suggest that wage growth has been broadly in line with productivity and alludes to the historically high level of wages, together with weak business environment, as key constraints on competitiveness.

\section{A. Introduction}

1. Croatia's pre-crisis growth performance was built on weak fundamentals. ${ }^{2}$ The robust growth performance recorded from 2002-08 was driven by abundant capital inflows, which fueled a credit boom, spilled over into large current account deficits, and resulted in a buildup of foreign liabilities. External funding was mainly in the form of debt-creating flows, with the majority of FDI going to the financial sector. This had the effect of further tilting the structure of the economy away from the tradable sector.

\section{Sustainable long term growth would require a rebalancing of the economy from} domestic to external demand. Domestic demand is likely to remain subdued over the near term as worldwide deleveraging from the high pre-crisis level is likely to moderate the extent of future capital inflows, while domestic deleveraging is likely to temper the demand for credit. In this context significant rebalancing through expansion of the tradable sector is needed to promote sustained economic growth.

\section{Croatia's export performance over the past decade suggests that external} competitiveness is relatively weak and serves as a binding constraint on growth. Weak competitiveness is largely due to relatively high labor cost. This along with existing structural weaknesses suggests that urgent reforms to facilitate wage adjustment and improve the business environment are needed to improve competitiveness and export performance.

\section{B. Key Findings}

\section{Movements in ULC and productivity at the disaggregated level suggest that} increases in unit labor cost from 2000-08 were not out of line with the regional average. In addition the gaps between productivity and wage growth (measured by difference between productivity growth and wage growth) were broadly in line with the sample average. Despite

\footnotetext{
${ }^{1}$ Prepared by Reginald Darius

${ }^{2}$ The discussion of Croatia's growth model follows the analysis of growth experiences in Eastern Europe detailed in Atoyan, R., 2010, "Beyond the Crisis: Revisiting Emerging Europe's Growth Model," IMF Working Paper 10/92 (Washington: International Monetary Fund).
} 
the growth in wages at the individual commodity export level, which is broadly in line with its comparators, Croatia's export performance in almost every product was at the lower end of the range of the countries in the sample. This represents a slight puzzle as growth in ULC which was broadly in line with that of comparator countries would imply that competitiveness was not significantly eroded during the past decade.

\section{The paper finds that the wage differential between Croatia and comparator} countries has declined over the past decade, however the wage level remain above the sample average, which suggest that weak export performance may be affected by the traditionally high level of wages, combined with numerous weaknesses in the business environment. With external demand likely to be lower than in the pre-crisis period, at least in the near-term, further reducing the wage gap between Croatia and its regional peers appears even more crucial than in the past to improve export performance.

6. The remainder of the paper is organized as follows. Section $\mathrm{C}$ examines developments in the external sector and particularly the trade deficit and the link between current account deficit and the buildup of vulnerabilities. Section D examines recent export performance, while section E examines wage, productivity, and export growth by commodity. The final section presents some conclusion and policy issues to consider.

\section{Current Account Balance and External Vulnerabilities}

\section{Relatively persistent current account deficits alongside weak export} performance are symptoms of an underlying competitiveness problem. During 2000-08, the current account deficit averaged 5.6 percent of GDP. The trade deficit averaged about 20 percent of GDP, with import growth buoyed by rapid increase in domestic demand during the boom period exceeding export growth. During that period the savings investment balance deteriorated due largely to an increase in investment in the non tradeable sector. The subsequent improvement in the current account deficit, during the period of severely weakened economic activity was due to a significant contraction in import demand as exports also plunged during the crisis but recovered at a faster rate.

8. The current account deficit was mainly financed by external debt. This resulted in a significant build up of vulnerabilities, which exposed the economy to financing risk. During the period (2000-2008) external debt rose from 52 percent of GDP to about 80 percent of GDP. A large proportion of the increase in debt was due to borrowing by banking sector, which was used to finance the domestic consumption boom rather than investment. 


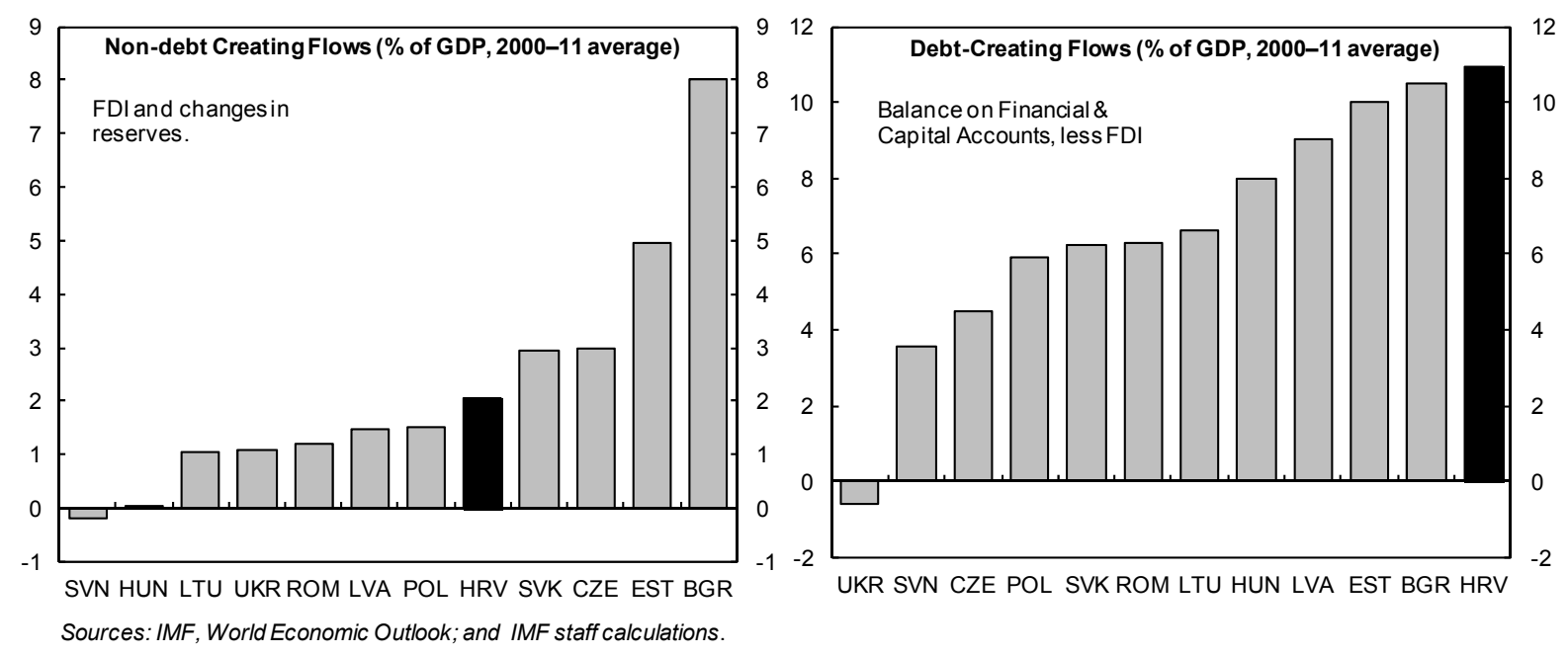

\section{Export Performance and Market Share Analysis}

9. Croatia's export performance has been

weak. The contribution of external demand to growth was negative during the boom years, 2001-2008. Following the economic crisis the contribution of external demand to growth improved with positive contributions in 2009 and 2010 due in part to the collapse in domestic spending.

\section{Croatia's rate of export growth was} amongst the slowest in this sample of Eastern

European countries from 2000-2008 ${ }^{3}$. Total export growth averaged about 15 percent the lowest rate recorded by any of the countries in this group. During the economic crisis when most countries suffered a significant collapse in export growth, Croatia was amongst the hardest hit. Export growth contracted by an annual average rate of almost 4 percent in 2009-2011, the worst performer among its peers.
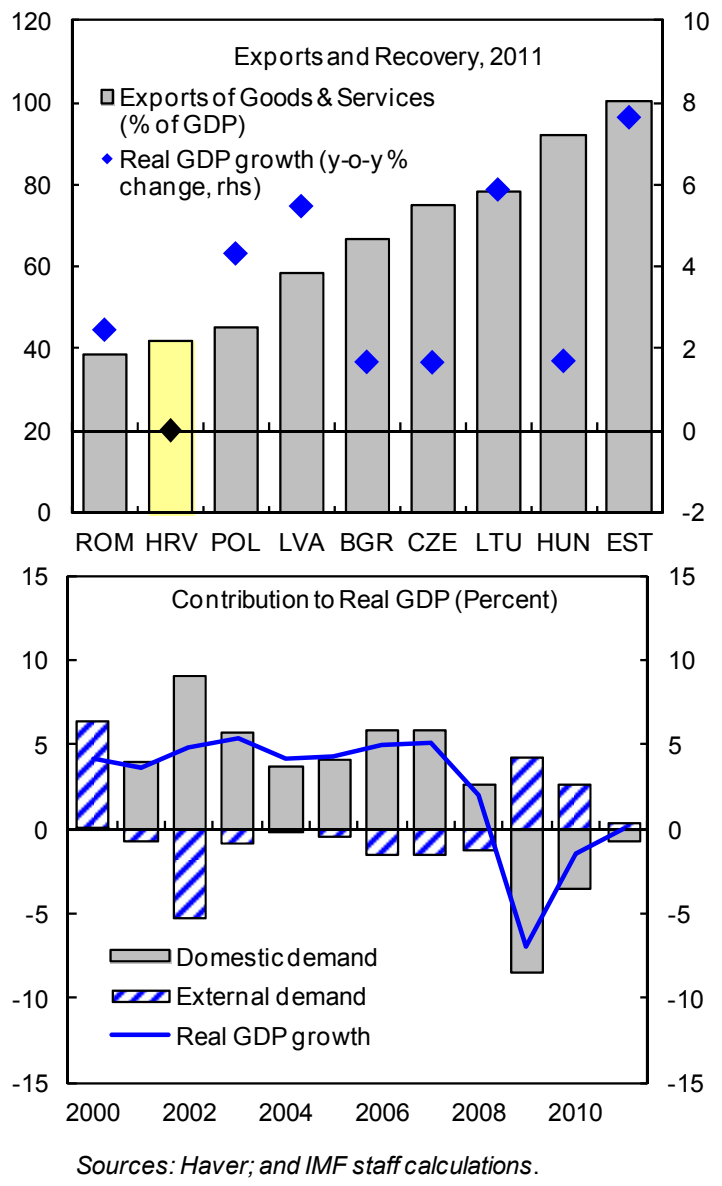

\footnotetext{
${ }^{3}$ Countries included in the analysis are Bulgaria, Croatia, Czech Republic, Estonia, Hungary, Latvia, Lithuania, Poland, Romania, and Ukraine.
} 

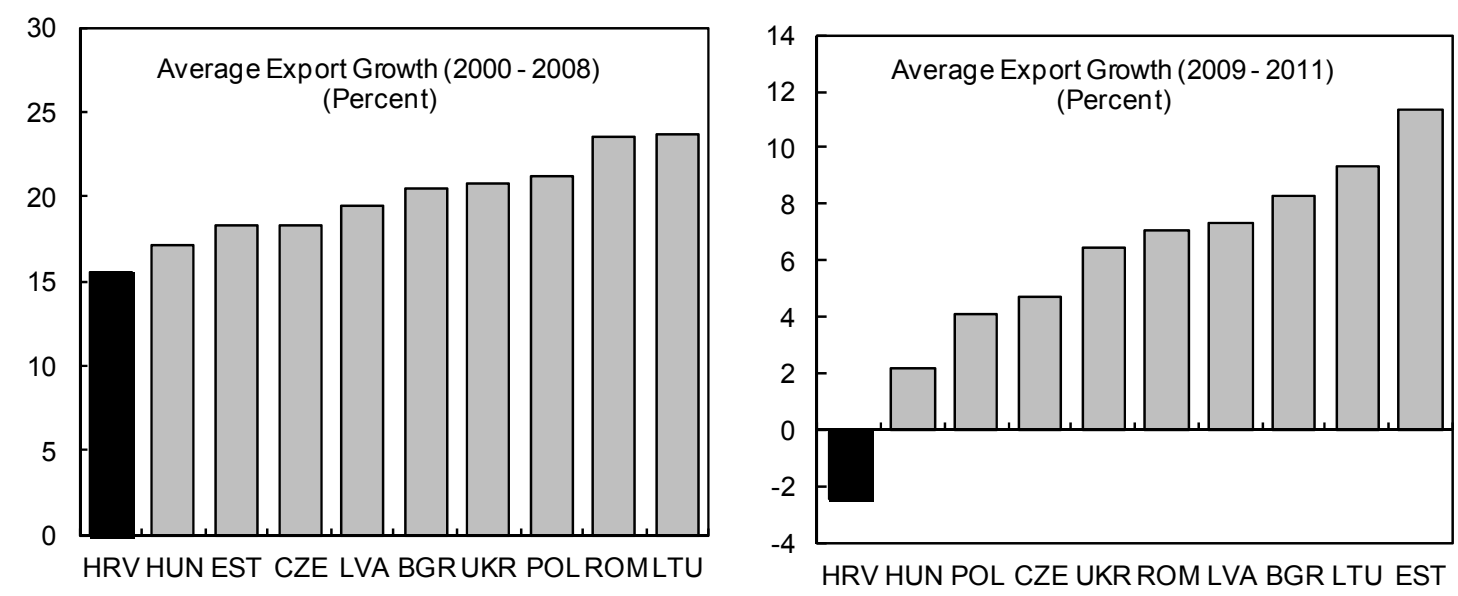

Source: WEO, and IMF Staff calculations.

11. The EU is Croatia's main commodity export market. Croatia's share of EU's imports remained relatively stagnant over the past decade. About 60 percent of Croatia's exports are destined to the EU. The EU also serves as the main market for the other countries in the sample - with the exception of Ukraine - purchasing on average in excess of 60 percent of their export goods. Croatia's share of the EU market is relatively small and falls within the lowest percentile relative to the other countries in the sample. Furthermore Croatia has made limited gains in improving on its percentile ranking over the past decade.
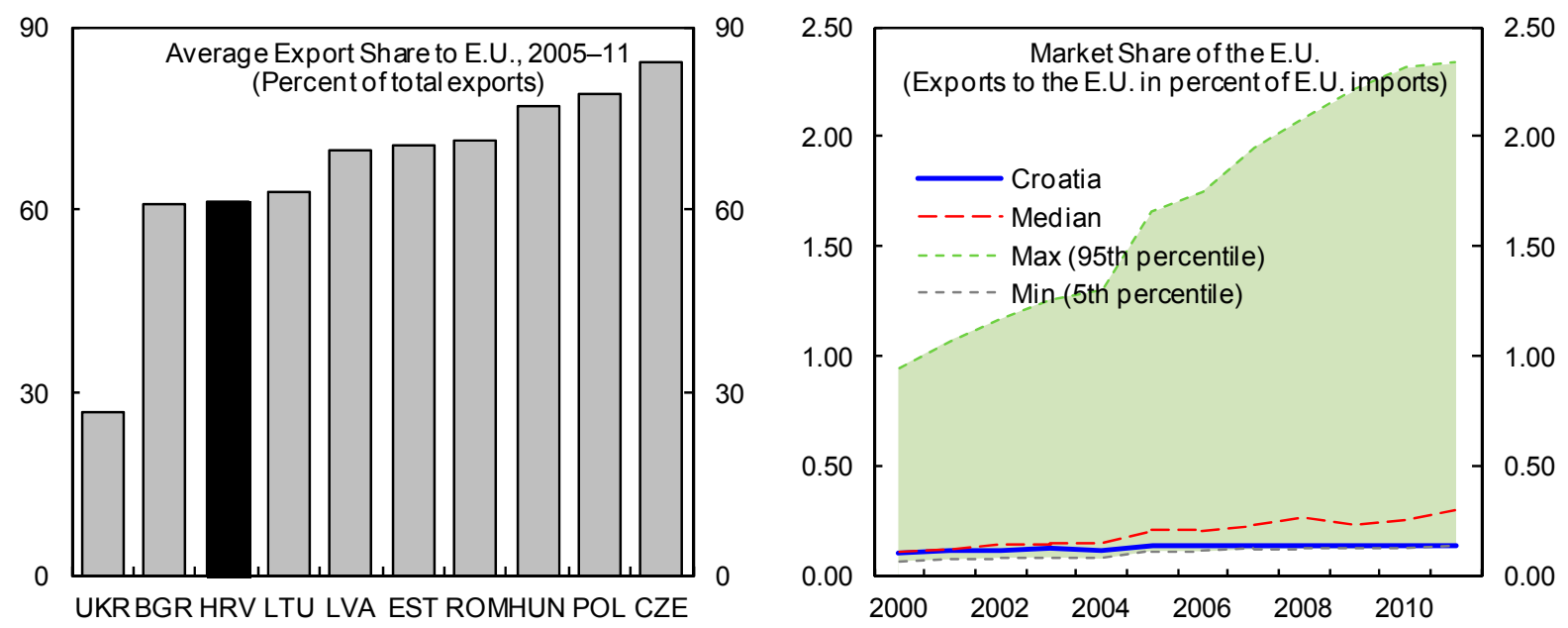

Sources: IMF, Direction of Trade statistics; and IMF staff calculations.

\section{Croatia was also unsuccessful in making inroads into the non EU market}

(Figure 1). The share of world imports accounted for by Croatia was in the lowest percentile and with minimal change over the past decade. A more disaggregated analysis suggests that Croatia was able to retain its market share in most markets but made limited strides in improving its position. A notable exception was the increase in market share to oil exporting countries, particularly following the onset of the global economic crisis. 
13. Commodities export is dominated by intermediate and consumer goods. Over the past decade, intermediate and consumer goods accounted for about 60 percent of commodity exports. The contribution of these commodities has remained remarkably stable. Capital goods accounted for about 20 percent of commodity exports during that period, suggesting that Croatia made limited headway in moving to the higher end of the export market.

\section{The export sectors did not benefit much} from the strong growth in capital inflows.

Greenfiled FDI into the tourism sector was relatively low, while inflows into the manufacturing sector were modest. The majority of the external

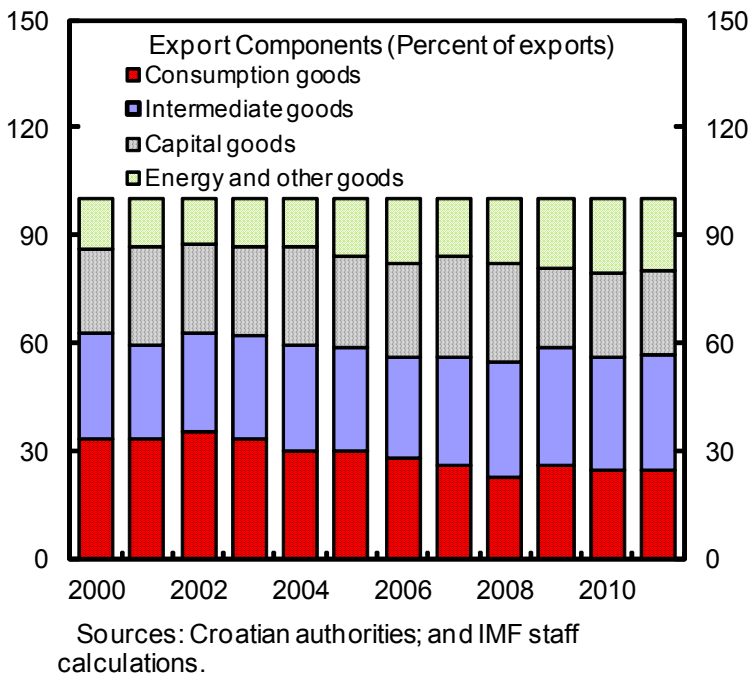
inflows made only limited contribution to improving competitiveness. On a cross country basis the average amount of FDI to the manufacturing sector was lowest in Croatia and this would partially explain the relatively weak export performance during that period. However within the manufacturing sector there appears to be limited causal link between FDI and export growth.

Aver age FDI and Export Growth by Sector (2000-2008)

\begin{tabular}{lcc}
\hline & FDI & Export \\
\hline Manufacture of chemicals and chemical products & 4.96 & 6.38 \\
Manufacture of other non -metallic min eral products & 2.86 & 10.50 \\
Manufacture of food produ cts and beverages & 2.27 & 15.09 \\
Manufacture of fabricated metal products & 0.36 & 17.67 \\
Publis hing, printing and reproduction of recorded & 0.59 & 4.30 \\
Manufacture of rubber and plastic products & 0.39 & 6.86 \\
Manufacture of textiles & 0.44 & $\mathbf{5 . 7 5}$ \\
Manufacture of pulp, paper and paper products & 0.15 & 9.72 \\
Manufacture of machinery and equipment n. e. c. & 0.41 & 14.97 \\
Tanning and dressing of leather & 0.17 & 4.59 \\
\hline
\end{tabular}


FDI flows into key Export Sectors

\begin{tabular}{|c|c|c|c|c|}
\hline & \multicolumn{2}{|c|}{$(2000-2010)$} & \multirow{2}{*}{$\begin{array}{l}(2007-09) \\
\text { Romania }\end{array}$} & \multirow{2}{*}{$\begin{array}{c}(2004-09) \\
\text { Czech Rep. }\end{array}$} \\
\hline & Croatia & Bulgaria & & \\
\hline Proportion of FDI to Manu. & 8.53 & 20.58 & 31.75 & 36.38 \\
\hline Proportion of FDI to Hotels & 3.62 & 1.59 & 0.48 & 10.37 \\
\hline
\end{tabular}

\section{E. Wages and Export Performance: A Micro Analysis}

15. Croatia's relatively high wages is a drag on competitiveness. Nominal wages in the manufacturing sector are high relative to peers and when compared to income and productivity levels. While productivity levels in Croatia's industrial sectors are not low, wages remain above the level consistent with existing levels of productivity. Not only are wages high but the overall employee compensation is high in Croatia.
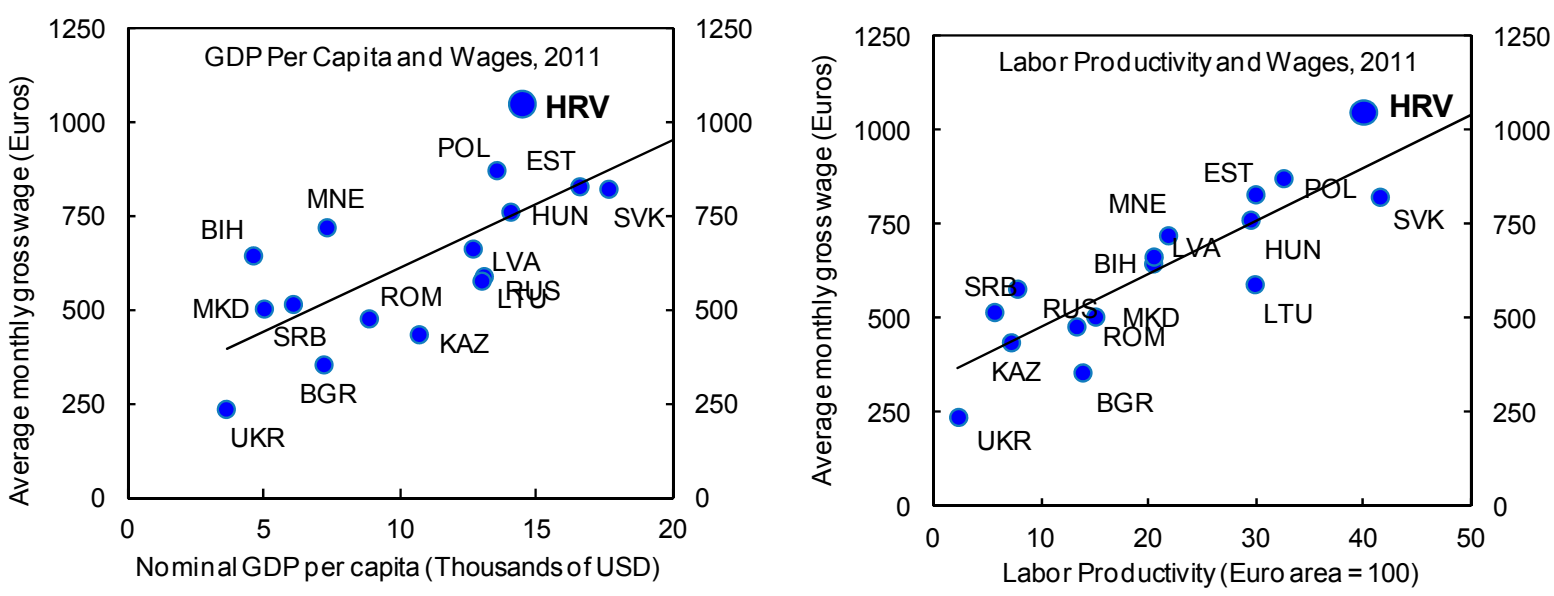

Sources: IMF, World Economic Outlook; and IMF staff estimates and calculations.

16. Detailed cross country data on ULC, productivity, wages and exports by manufacturing sub-sectors provides the basis for a micro assessment of Croatia's export competitiveness. The Vienna institute publishes detailed information on export data for a number of Eastern European countries including Croatia. The information contained in this database allows for a micro level analysis of the role of cost and productivity in export performance. The database includes information on manufacturing products identical to the 2-digit level of ISIC Rev. Code 3 (23 industries) and also total industry (mining and quarrying, manufacturing, and electricity, gas steam and water supply). The data includes industrial production by sub-sector, unit labor cost, wages and productivity.

\section{This analysis focuses on a selected subset of manufacturing products for which}

data is available. Products are chosen based on export value with the threshold of at least EUR 250 million to the EU market in 2008, the last year for which the relevant data is available, and a second group of high-end/high-value products is also included. Nine sub- 
sectors met the minimum value threshold. In the high-end category five sub-sectors are included, with electrical machinery falling into both categories.

\section{Overall industrial and manufacturing sector data suggest that Croatia's annual} average growth in ULC was relatively low (Figure 2). Annual average ULC growth of the manufacturing sector was well below five percent, only Hungary and Poland recorded a slower rate of increase. Despite the relatively slow rate of growth in ULC, Croatia recorded the lowest average annual export growth (less than 10 percent), while every other country recorded export growth in excess of 10 percent. A similar picture emerges in the case of industry exports, where labor cost was the third lowest; however, export growth lagged that of all but four countries in the grouping.

19. At the more disaggregated level there was broad consistency with the trend observed in the manufacturing sector of relatively low growth in ULC alongside comparatively weak export performance (Figure 2-5). This is particularly apparent in the case of food products, chemical products, electrical machinery and machinery and equipment. Notable exceptions include apparel, transport equipment and wood products. The performance of apparel exports appears to have been affected by price competitiveness. Exports of apparel products registered the third largest decline of the countries in the group of about 5 percent, while ULC increased by about 7 percent, and the fall in wages was much lower than then the decline in productivity. Export of transport and equipment registered big gains, alongside increased ULC of about 5 percent but the positive gap between productivity and wage growth was relatively high. Export of wood products and textiles also grew at a comparatively high rate and was supported by productivity gains which far exceeded wage increases.

20. Croatia's performance in high technology export was below average (Figure 6). With the exception of office machinery and communication equipment -mainly due to the base effect- export growth in relatively high technology products were generally below par. Average export growth of both office machinery (about 45 percent) and communication equipment (about 20 percent) was impressive. However these outcomes should be viewed with some caution given the small starting position. Medical products registered an average annual export growth of about 10 percent despite relatively modest growth in ULC and the very low base. Publishing and printing had a similar pattern, Croatia, despite been the only country to record an average decline in ULC, recorded the second lowest export growth in the group.

21. The relative gap between productivity and wage does not appear to exert much influence on Croatia's export performance (Table 1). Despite having a higher gap between wages and productivity in key export categories, Croatia's export growth was lower for total industry and manufacturing products along with the subgroups; food products, machinery and equipment, chemical products and publishing and printing. These results are in direct contrast to what would have been expected. The outcome for wood products was more in line 
with the norm, where the larger gap between productivity and wages resulted in a more favorable export performance. Transport and equipment also provided a non standard outcome in the opposite direction, where despite wage growth exceeding that of productivity export performance was better than the average.

Table 1: Export Growth Productivity and Wage Gap (P-W)

\begin{tabular}{|c|c|c|c|c|c|c|}
\hline & \multicolumn{3}{|c|}{ Gap } & \multicolumn{3}{|c|}{ Export Growth } \\
\hline & Avg. Gap & HRV Gap & Gap diff. & $\begin{array}{c}\text { Avg. Export } \\
\text { Growth }\end{array}$ & $\begin{array}{c}\text { HRV Export } \\
\text { Growth }\end{array}$ & Growth diff \\
\hline Transport equip. & 2.8 & -0.9 & -3.8 & 28.3 & 53.7 & 25.4 \\
\hline Office machinery & 16.8 & -9.8 & -26.6 & 35.6 & 46.0 & 10.4 \\
\hline Communication equip. & 8.1 & -2.8 & -10.9 & 23.8 & 23.9 & 0.1 \\
\hline Food products & 1.2 & 2.3 & 1.1 & 20.7 & 15.1 & -5.6 \\
\hline Machinery and equip. & 6.3 & 6.5 & 0.2 & 21.2 & 15.0 & -6.2 \\
\hline Medical instruments & 5.3 & 2.5 & -2.9 & 19.9 & 10.1 & -9.8 \\
\hline Electrical machinery & 3.1 & 1.9 & -1.2 & 17.7 & 9.7 & -8.1 \\
\hline Total industry & 1.5 & 1.8 & 0.3 & 15.9 & 8.5 & -7.4 \\
\hline Manufacturing & 2.0 & 2.2 & 0.2 & 15.5 & 8.4 & -7.1 \\
\hline Wood products & 1.4 & 3.4 & 2.1 & 5.7 & 8.0 & 2.3 \\
\hline Chemical products & 3.6 & 2.2 & -1.4 & 18.4 & 6.4 & -12.1 \\
\hline Textiles & 2.7 & 1.6 & -1.0 & 5.1 & 5.7 & 0.6 \\
\hline Publishing and printing & 2.1 & 6.6 & 4.5 & 17.0 & 4.3 & -12.7 \\
\hline Apparel & 0.2 & -2.9 & -3.1 & -0.9 & -5.2 & -4.3 \\
\hline
\end{tabular}

Gap measures the difference between productivity growth and wage growth.

The average gap is the average of the difference between productivity and wages of the countries included in the sample Source: Vienna Institute for International Economic Studies; and IMF staff calculations

\section{Export growth is strongly correlated to productivity and ULC growth for a few}

low value added commodities. Exports of other transport equipment and electrical machinery are strongly correlated with both ULC and productivity-although in the case of the electrical machinery the correlation with productivity growth has the wrong sign (Table 2). Export growth of textiles, and food and beverage are also strongly correlated with productivity and ULC growth. This suggests that for some major export categories the outcome is in line with the expectation that increasing productivity would result in a significant boost to exports. 
Table 2. Export, ULC and Productivity growth (correlation)

\begin{tabular}{lcc}
\multicolumn{3}{c}{ (2000-2008) } \\
\hline \multicolumn{1}{c}{ Commodity } & $\begin{array}{c}\text { Correlation Coefficient } \\
\text { Exports }\end{array}$ & $\begin{array}{c}\text { Productivity } \\
\text { and Exports }\end{array}$ \\
\hline Radio, TV and communications & 0.47 & -0.20 \\
Medical & 0.42 & -0.36 \\
Total Industry & 0.29 & 0.33 \\
Manufacturing & 0.16 & -0.35 \\
Wearing Apparel & -0.06 & 0.10 \\
Publishing, printing etc & -0.12 & -0.06 \\
Machinery and Eqp. & -0.13 & 0.07 \\
Chemicals & -0.24 & 0.31 \\
Wood and wood products & -0.30 & 0.15 \\
Food products and Beverages & -0.50 & 0.62 \\
Textiles & -0.55 & 0.51 \\
Other Transport Eqp. & -0.58 & 0.62 \\
Electrical machinery & -0.64 & -0.73 \\
\hline Source: Vienna Institute for International Economic Studies; \\
and IMF staff calculations & &
\end{tabular}

\section{Croatia made limited headway in boosting its market share of specific export} items. This finding is broadly consistent with what was observed at the aggregate level (Table 3). Detailed examination of market share, relative to the group of countries in the sample, suggests very minimal gains. In fact, the trends in market share at various points $(1999,2003$, and 2008) indicate that of the thirteen products considered, only in three instances was the market share in 2008 higher than in 2000. Relatively significant improvements was recorded in transport and equipment (4.5 percent gain) and to a lesser extent communications and equipment. However market share was lost in chemical products ( 3 percent), apparel ( 2 percent) and medical instruments ( 0.5$)$ percent. 
Table 3. Market Share

(Exports of Eastern Europe to the European Union) 1/

In percent

\begin{tabular}{lcccc}
\hline & $\mathbf{1 9 9 9}$ & $\mathbf{2 0 0 3}$ & $\mathbf{2 0 0 7}$ & $\mathbf{2 0 0 8}$ \\
\hline Manufacturing & 3.04 & 2.31 & 1.75 & 1.68 \\
Total industry & 3.03 & 2.28 & 1.77 & 1.70 \\
Food products & 3.34 & 3.99 & 2.37 & 1.98 \\
Machinery and equip. & 2.6 & 1.7 & 1.9 & 1.9 \\
Transport equip. & 1.3 & 3.7 & 4.2 & 5.9 \\
Wood products & 5.61 & 4.36 & 4.11 & 4.07 \\
Textiles & 6.56 & 5.09 & 4.53 & 4.95 \\
Apparel & 5.85 & 3.94 & 3.21 & 3.06 \\
Chemical products & 6.4 & 3.9 & 2.7 & 2.6 \\
High end products & & & & \\
Electrical machinery & 2.12 & 1.32 & 1.09 & 1.14 \\
Medical instruments & 2.72 & 1.37 & 1.24 & 1.10 \\
Office machinery & 0.11 & 0.18 & 0.22 & 0.16 \\
Communication equip. & 0.15 & 1.99 & 1.02 & 0.87 \\
Publishing and printing & 3.33 & 2.00 & 1.26 & 1.31 \\
\hline
\end{tabular}

1/ Eastern Europe includes Bulgaria, Croatia, Czech Rep., Estonia, Hungary, Latvia, Lithuania, Poland, Romania, Slovak Rep., Slovenia, and Ukraine.

Source: Vienna Institute for International Economic Studies; and IMF staff calculations

24. The continued poor performance of Croatia's export cannot be clearly linked to developments regarding changes in cost and productivity. Croatia made limited strides in increasing its presence in key markets and actually lost market share in major export products. Interestingly, average ULC growth for many export goods and the manufacturing sector was comparatively low, even though productivity growth in a wide range of commodities was below average wage growth. These findings raise some interesting questions relating to Croatia's poor export performance. One clear outcome is that lower than average increases in wage cost appear to have minimal impact on export performance in the short run. This suggest that for Croatia to improve export performance it needs to record wage declines and or productivity increases which far exceeds that of competitor countries.

\section{High wages in Croatia partly reflects the legacy of pre transition period. The} overall increase in wage growth over the past decade is broadly in line with that of regional peers. This point is highlighted by looking at wage differentials on an annual basis from 2000-2008. This analysis suggests that Croatia's wages was above the average wage for the region at the start of the period under consideration and was significantly higher than that of the lower wage countries. The wage gap between Croatia and its regional peers have been reduced over the years, which suggest that wage growth has not been particularly rapid, and the wage competitiveness gap reflects some degree of inertia. 


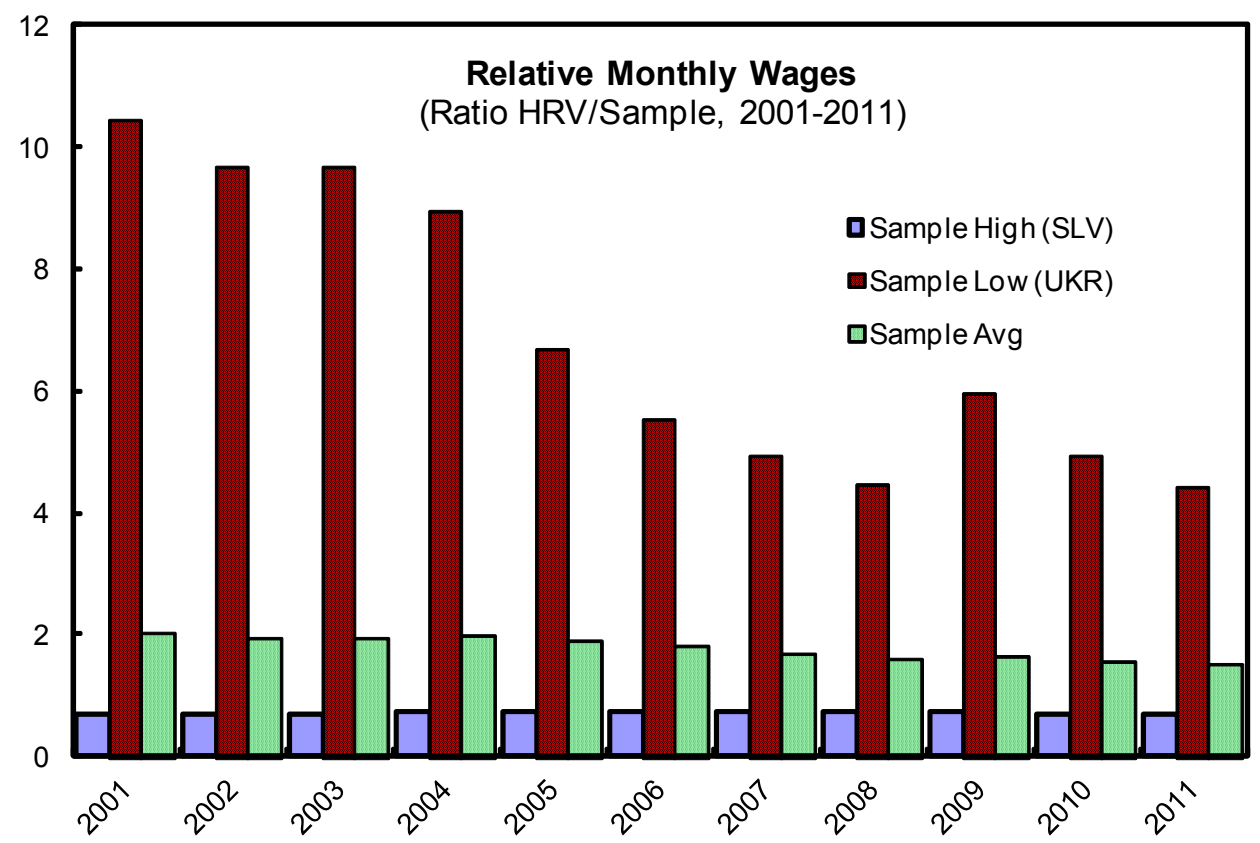

Source: WEO, IMF Staff Estimates. Sample includes CESEE countries.

\section{F. Conclusion}

The result of this analysis suggests that Croatia's high wage level is a major drag on export performance. Disaggregated analysis of export products, suggest that wage growth has been broadly in line with productivity and alludes to the historically high level of wages as key constraint on price competitiveness. High wage level, together with weak business environment, appears to have limited export performance. This implies that the policy priority of the authorities should be on measures to contain or reduce the level of wages along with structural measures to improve business environment and labor market flexibility. This would result in an improvement in competitiveness, that would contribute towards reducing the external financing requirement. Despite the recent improvements in the current account deficit, financing requirements remains elevated and is projected to exceed 20 percent of GDP over the near term. Reducing the financing requirement and the associated risk would be aided by an improvement in overall competitiveness. This would boost exports, improve the external balance and increase the availability of domestic resources to finance investment, which would also lead to a gradual reduction in the external debt burden. 


\section{Appendix}

Figure 1: Market Share, 2000-11
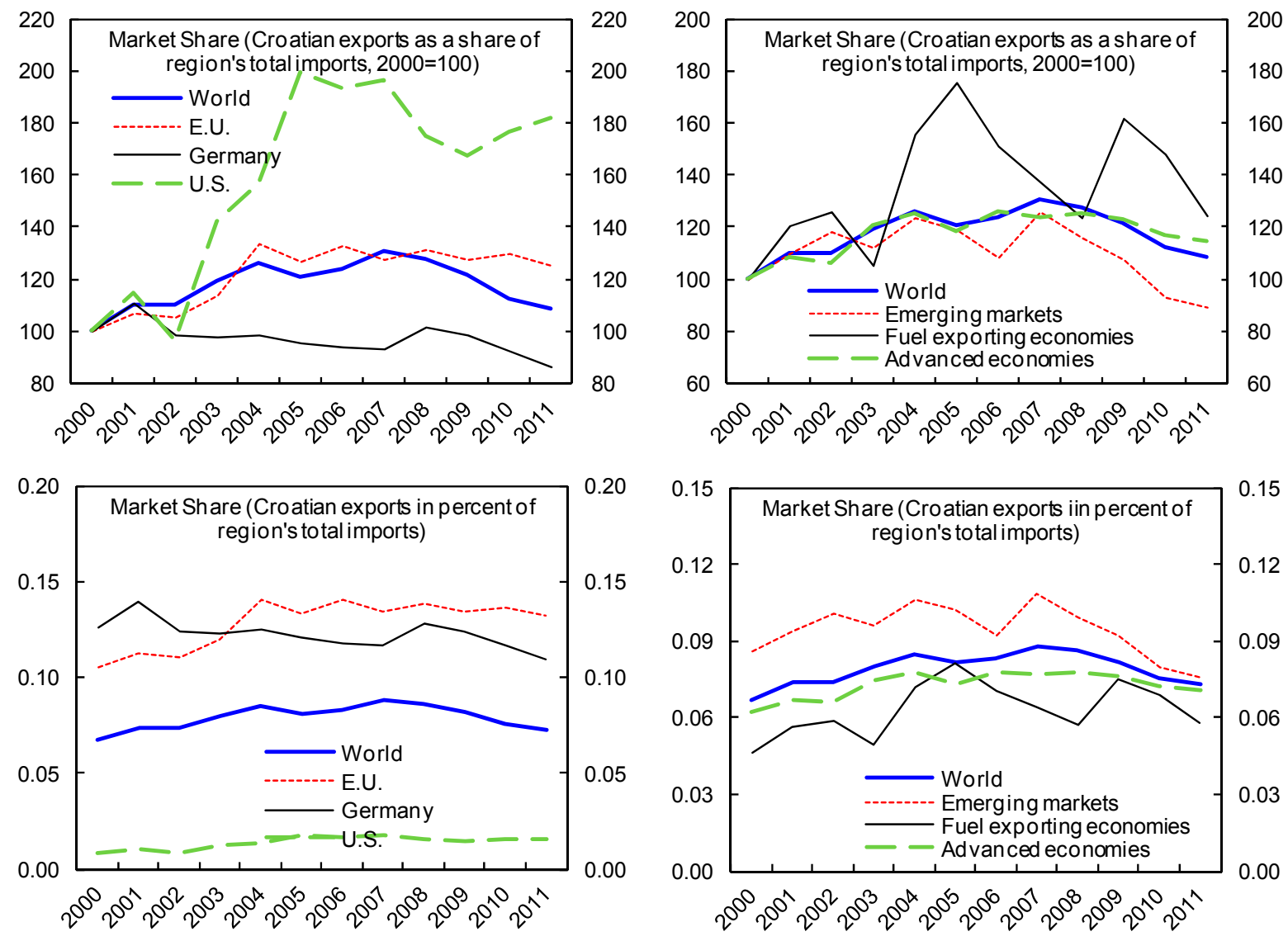

0.20

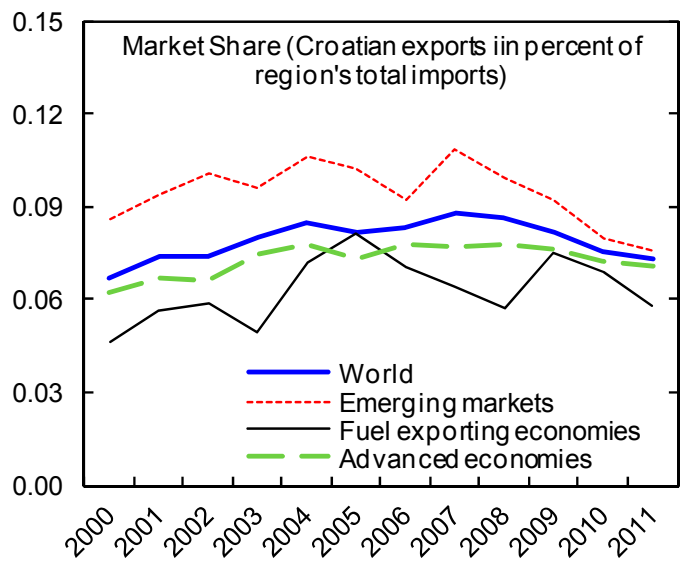

0.15

0.15

0.10
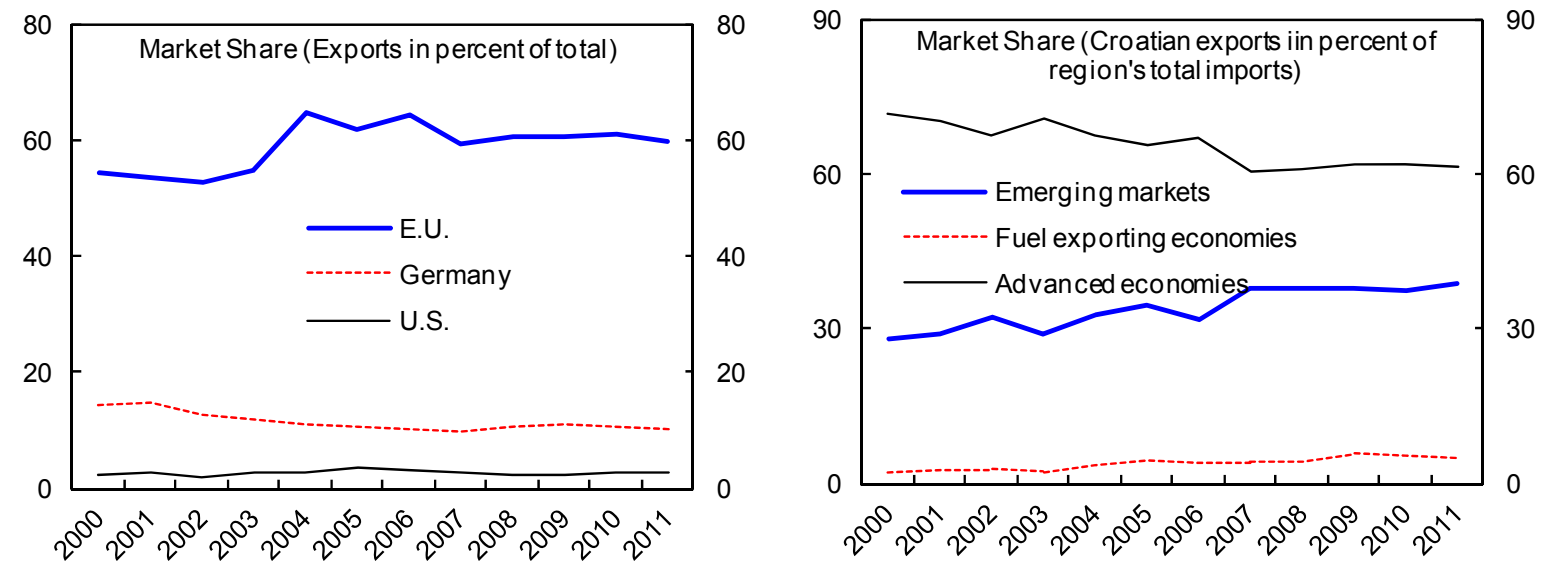

Source: IMF, Direction of Trad e Statistics and IMF staff calculations. 
Figure 2: Eastern Europe: Export and ULC, 2000-08

(Percent)
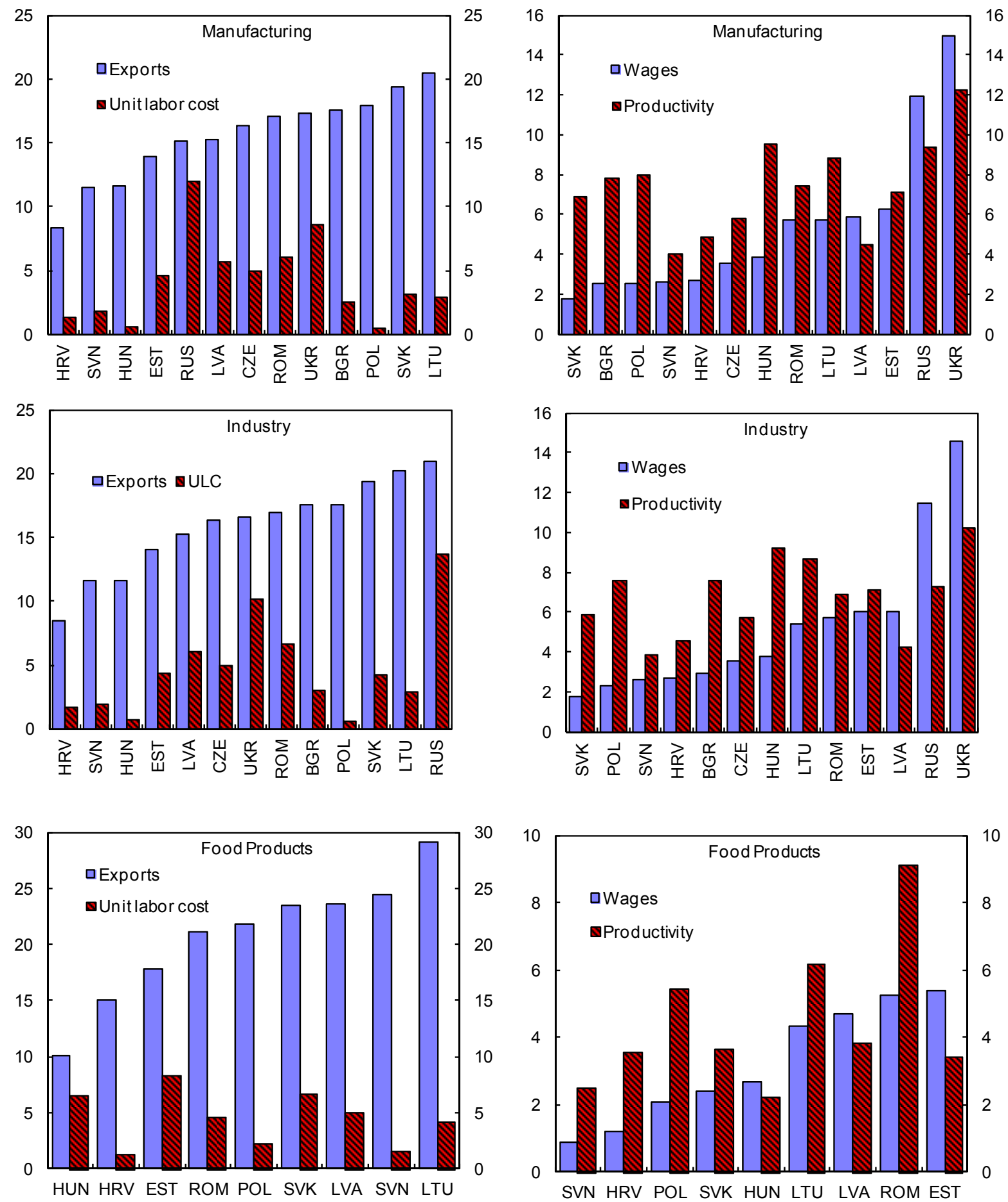

Sources: Vienna Institute for International Economic Studies; and IMF staff calculations. 
Figure 3. Eastern Europe: Export and ULC, 2000-08

(Percent)
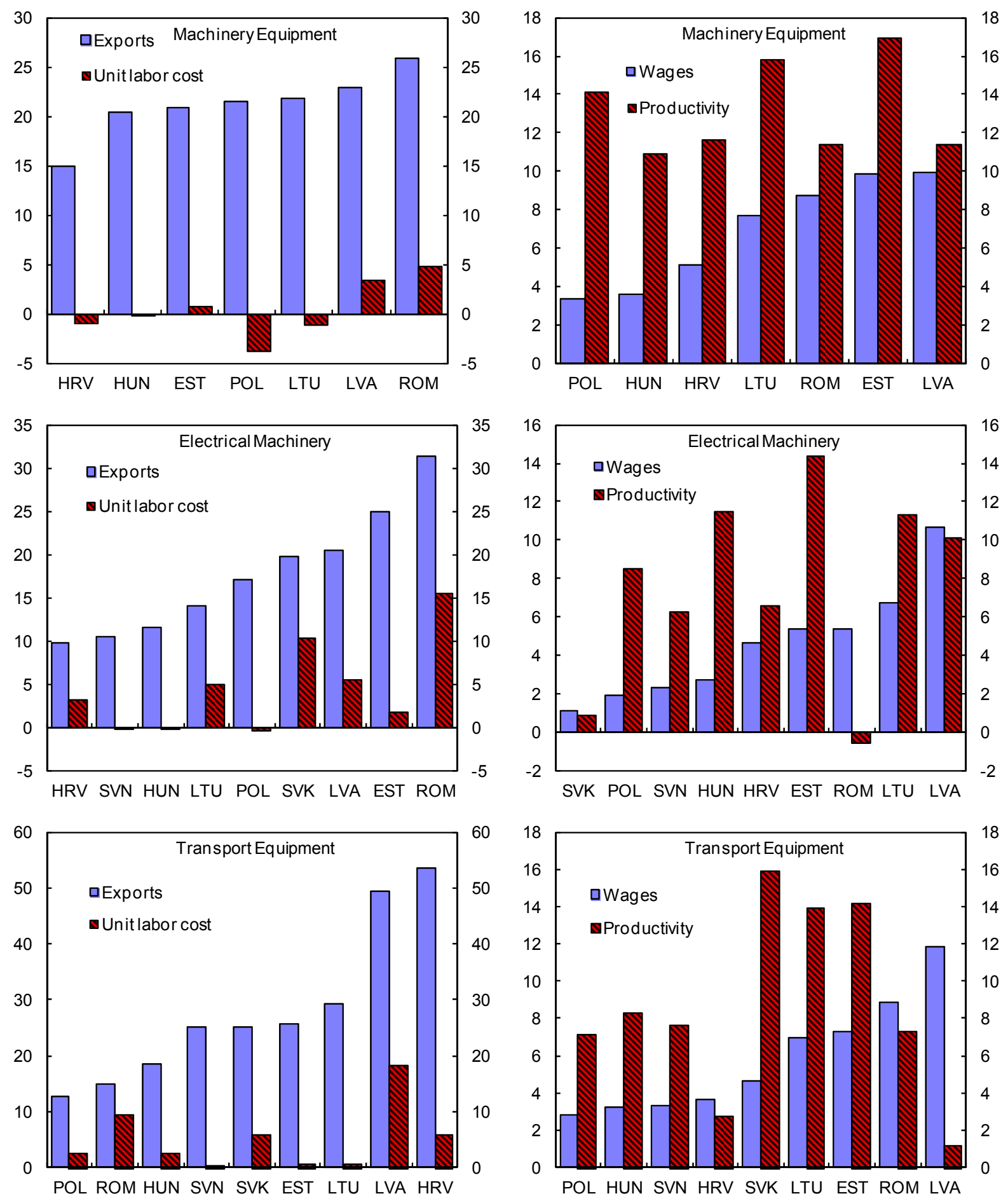

Sources: Vienna In stitute for Intemational Economic Studies; and IMF staff calculations. 
Figure 4: Eastern Europe: Export and ULC, 2000-08

(Percent)
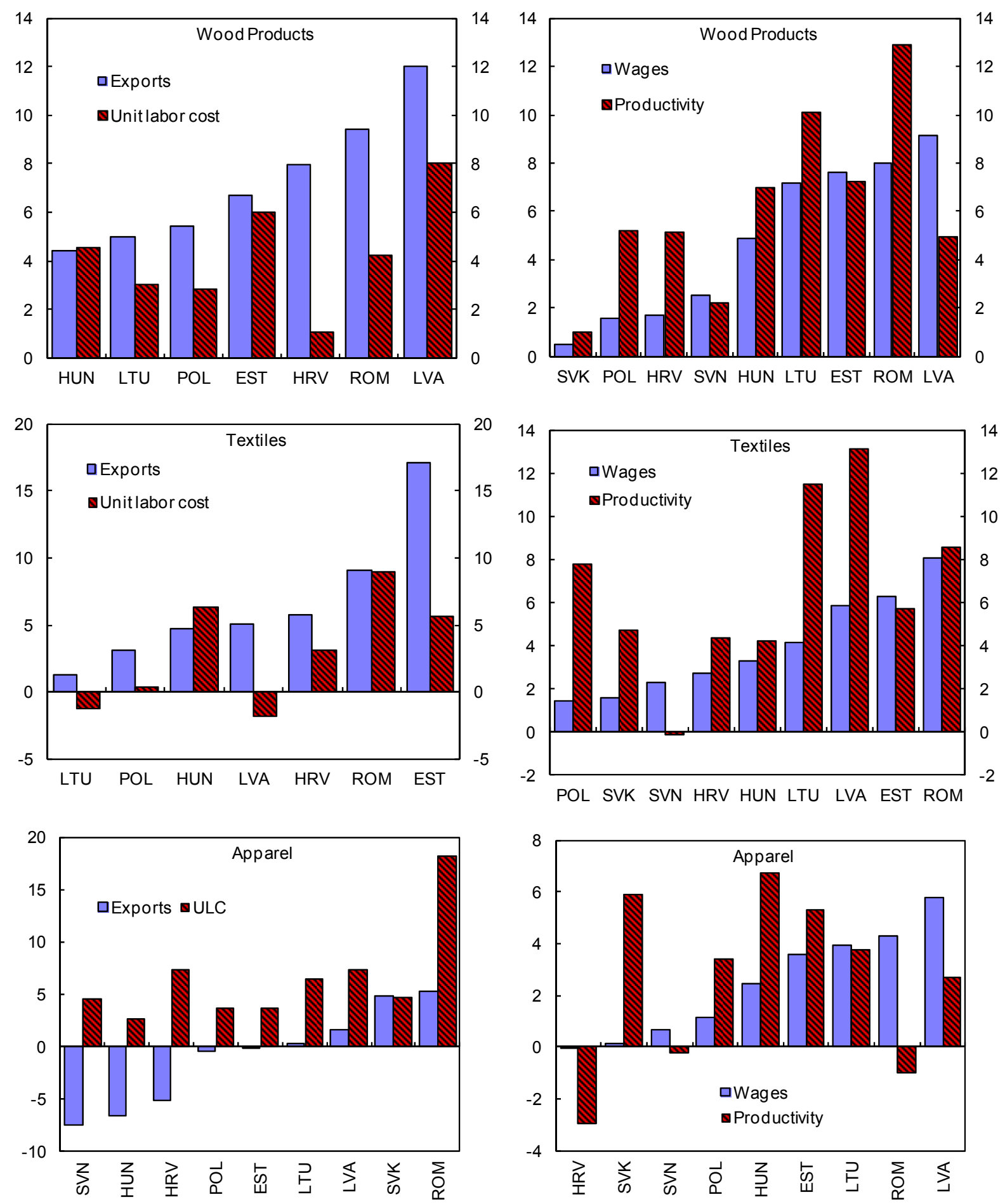

Sources: Vienna Institute for Intemational Economic Studies; and IMF staff calculations. 
Figure 5. Eastern Europe: Export and ULC, 2000-08

(Percent)
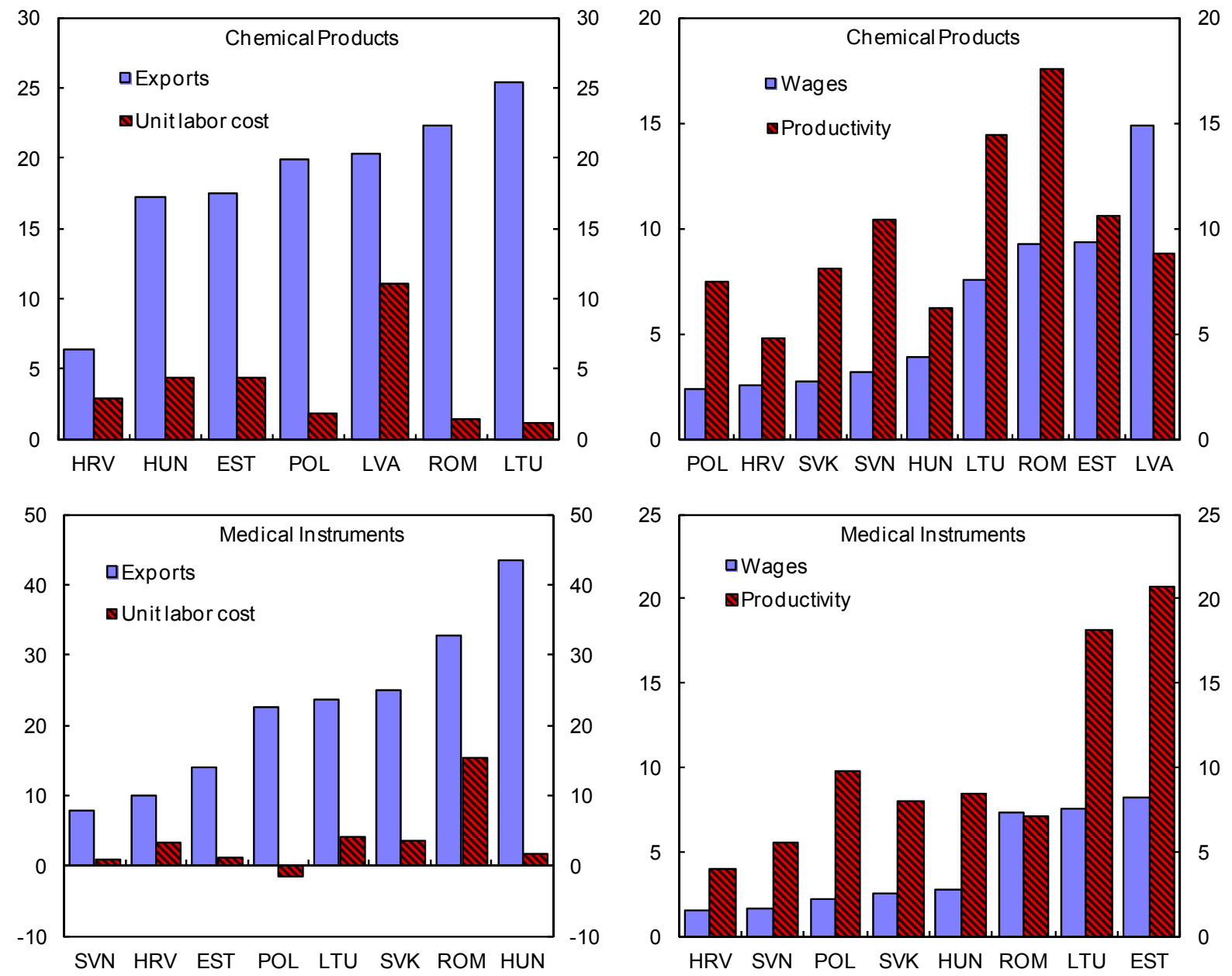

Sources: Vienna Institute for Intemational Economic Studies; and IMF staff calculations. 
Figure 6. Eastern Europe: Export and ULC, 2000-08

(Percent)
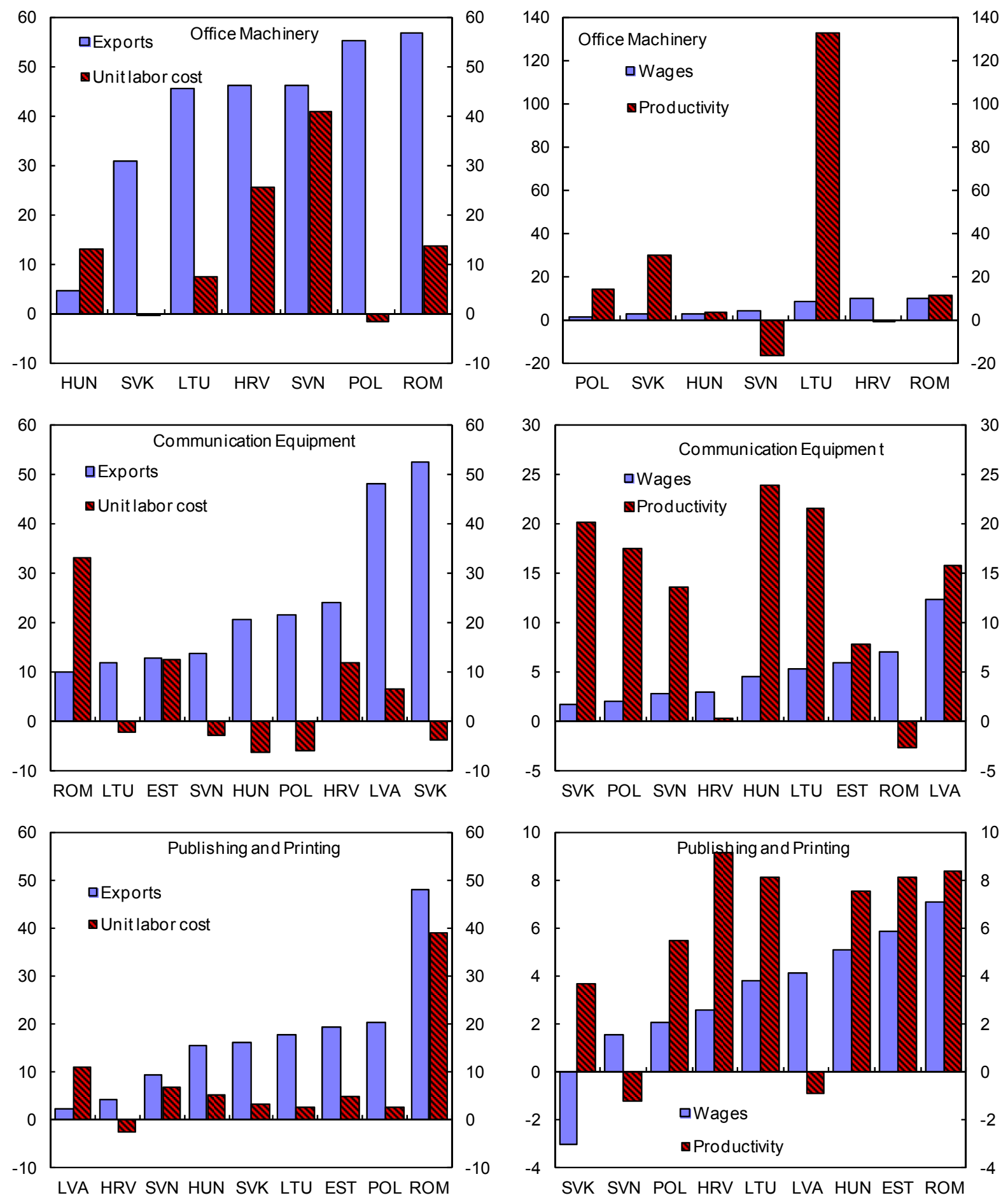

Sources: Vienna In stitute for Intemational Economic Studies; and IMF staff calculations. 